Maurer School of Law: Indiana University

Digital Repository@ Maurer Law

Indiana Law Journal

Volume 93 | Issue 3

Article 4

Summer 2018

\title{
Hands on the Wheel: A Call for Greater Regulation of Semi- Autonomous Cars
}

Tracy Pearl

Texas Tech University, tracy.pearl@ttu.edu

Follow this and additional works at: https://www.repository.law.indiana.edu/ilj

Part of the Legislation Commons, and the Transportation Law Commons

\section{Recommended Citation}

Pearl, Tracy (2018) "Hands on the Wheel: A Call for Greater Regulation of Semi-Autonomous Cars," Indiana Law Journal: Vol. 93 : Iss. 3 , Article 4.

Available at: https://www.repository.law.indiana.edu/ilj/vol93/iss3/4

This Article is brought to you for free and open access by the Law School Journals at Digital Repository @ Maurer Law. It has been accepted for inclusion in Indiana Law Journal by an authorized editor of Digital Repository @ Maurer Law. For more information, please contact rvaughan@indiana.edu.

\section{$\Psi$}

JEROME HALL LAW LIBRARY

INDIANA UNIVERSITY

Maurer School of Law
Blooming ton 


\title{
Hands on the Wheel: A Call for Greater Regulation of Semi-Autonomous Cars*
}

\author{
TRACY HREsko PEARL ${ }^{\dagger}$ \\ To the insider they exhibited only their attractive features; to the out- \\ sider, only their repulsive ones. To nearly everyone but the occupants \\ they were an inconvenience; to many a nuisance, and to some a veritable \\ terror. ${ }^{1}$
}

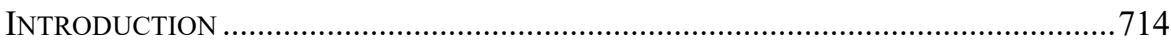

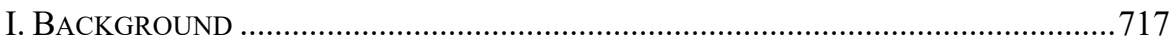

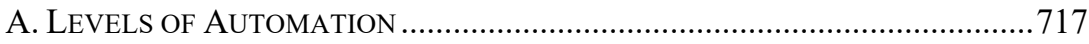

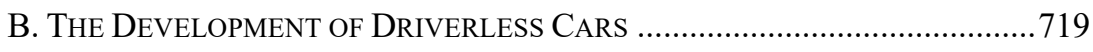

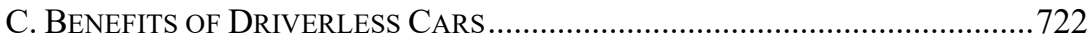

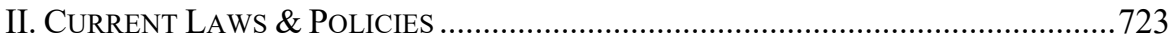

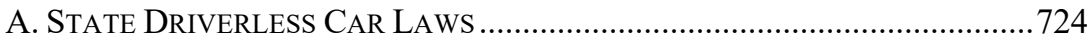

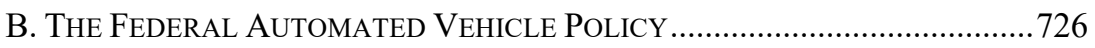

1. FoCUS ON LEVEL 3 VeHICLES AND ABOVE .......................................727

2. LACK OF A PREMARKet APPROVAL ProcesS .................................728

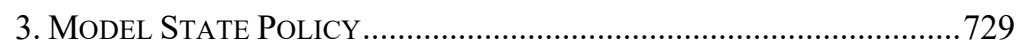

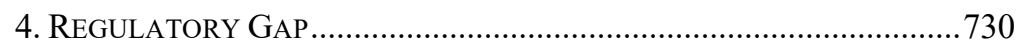

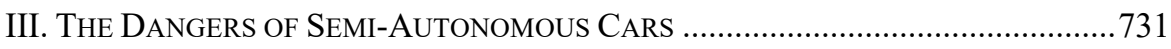

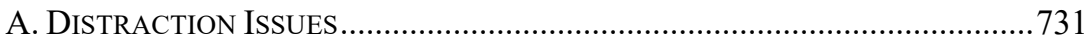

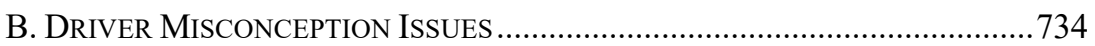

1. WRITTEN MANUALS AND ONSCREEN WARNINGS ...........................734

2. POORLY INFORMED SALESPEOPLE ………………….....................736

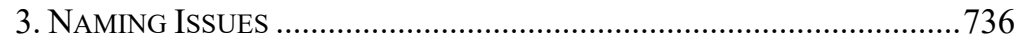

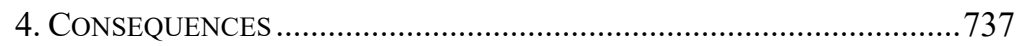

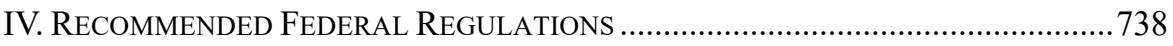

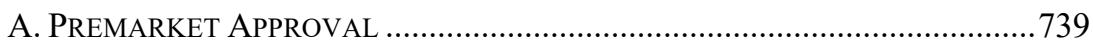

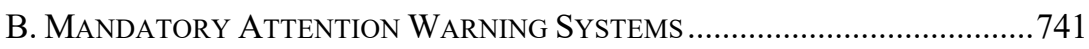

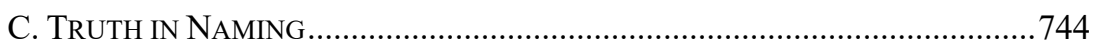

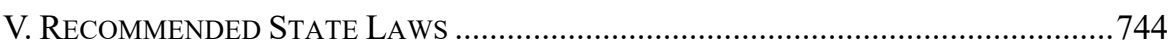

A. TAMPERING WITH OR DISABLING DRIVER MONITORING SYSTEMS ...........745

B. UPDATE AND MAINTENANCE REQUIREMENTS..........................................745

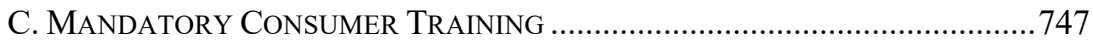

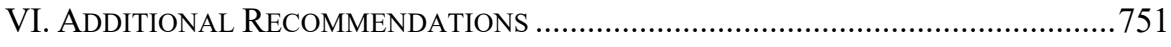

* Copyright (C) 2018 Tracy Hresko Pearl.

$\dagger$ Associate Professor of Law, Texas Tech University School of Law. J.D., Boston College Law School, 2006; M.Sc., Comparative Social Policy, Oxford University, 2003; A.B., Public Policy, Duke University, 2002. Many thanks to Professors M. Alexander Pearl, Vickie Sutton, and Marin Dell. I am also extremely grateful to my research assistant, Amanda Kraynok, for her meticulous and dedicated work, and to Michele Thaetig for her eye for detail. This article was made possible by a generous grant from Texas Tech University School of Law.

1. H.B. Brown, The Status of the Automobile, 17 YALE L.J. 223, 225 (1908). 


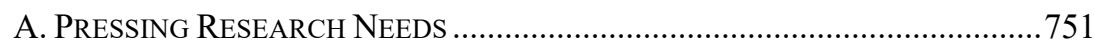

B. THE COMING ISSUES WITH LEVEL 3 CARS .............................................753

C. THE RISKS INHERENT IN LAWMAKING …............................................ 754

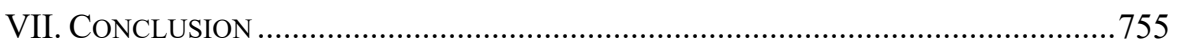

\section{INTRODUCTION}

There is a scene in the 1980 hit comedy film Airplane! that seems to predict the future. After the pilot of the eponymous airplane collapses in the cockpit and has to be dragged from his seat, he sputters to the flight attendant that she should turn on the "automatic pilot." She searches the control panel frantically and finds the right switch. Upon activating it, a plastic inflatable pilot complete with a pilot's jacket and hat springs up from the empty copilot's seat (the copilot having taken ill, as well) and smoothly assumes control of the plane, plastic inflatable hands on the yoke. Everyone is relieved until, moments later, the automatic pilot springs a leak and the plane begins to plummet towards the ground as he deflates. Panic ensues until the flight attendant is able to reinflate him successfully.

After the terrifying technical malfunction, however, everyone in the cockpit appears to feel overly confident in the automatic pilot's ability to keep the plane safely in the air, at least until the plane has to land. People come and go from the cockpit as they attempt to address other crises on the plane and engage in various comedic hijinks. Indeed, the blind trust of the characters in the patently absurd inflatable pilot is one of the funniest aspects of the cockpit scenes. We, as the audience, would presumably never trust a flimsy plastic "pilot" to fly an airplane without supervision (if at all), and so the characters' willingness to do so is both hilarious and horrifying.

Recent experience, however, teaches us that the automatic pilot scenes in Airplane! may, in fact, be strangely astute, at least with regard to human responses to automation. Over the last two years, many automobile manufacturers have begun introducing significant new forms of automation into their vehicles. Tesla, for example, has introduced "Autopilot" to its Model S, a premium feature that can keep the vehicle centered within a lane, maintain a constant speed, and brake when appropriate, thus eliminating the need for drivers to steer, accelerate, or brake while the Autopilot is functioning properly. ${ }^{2}$ The reliability of the feature, however, is limited. Tesla designed the "Autosteer" subsystem within Autopilot, for instance, only to work "on highways that have a center divider and clear lane markings." Accordingly, Tesla has gone to great lengths to warn drivers that they must continuously monitor their vehicles while using the Autopilot feature due to its significant limitations. ${ }^{4}$ Even a fairly short stretch of road with faded lane markings can cause an Autopilot-driven vehicle to veer into another lane, and so users of the feature must be extremely vigilant or risk a serious accident.

Many Tesla drivers, however, appear to view the risks of the Autopilot system very differently. Since the advent of Autopilot, the internet has been inundated with

2. Nat'l Highway Traffic Safety Admin., ODI Resume: Investigation PE 16-007, at 4 (2016), https://static.nhtsa.gov/odi/inv/2016/INCLA-PE16007-7876.PDF [https:// perma.cc/G8TW-PR92].

3. $I d$. at 8 .

4. Id. at 6 . 
videos of Tesla drivers paying little to no attention to their Autopilot-driven vehicles, even when those vehicles are driving at high speeds on major highways. Instead, the videos show Tesla drivers sleeping, playing games, dancing, and, much like the characters in Airplane!, moving out of the driver's seat and into other sections of the car and engaging in various comedic hijinks. All of this occurs, moreover, in spite of the fact that, unlike the characters in Airplane!, the Tesla drivers have received clear warnings about the limitations of the Autopilot system.

To be fair, Tesla's Autopilot system is far superior to and overwhelmingly less absurd than the plastic inflatable pilot in Airplane!. But Autopilot's appearance of safety may, in fact, make using it all the more dangerous. Unlike the plastic pilot in Airplane!, which looks amateurish and unreliable and thus should have inspired caution in the movie's characters, Tesla's Autopilot system is built into both the hardware and software of the car, has an impressive dashboard interface, and operates beautifully when used in optimal conditions. It provides an impressive illusion of being much more comprehensive and adroit than it actually is. Unsurprisingly, therefore, Tesla drivers have treated Autopilot-operated Teslas as being fully driverless when, in fact, they are only partially so and remain dependent upon constant human supervision to minimize their inherent risks. This disconnect-between perception and reality - has led to devastating consequences on occasion, as discussed at length below.

Tesla's Model S is not the only partially driverless ("semi-autonomous," in industry parlance) car currently on the market. As noted above, "[m]ost high-end cars from brands like Mercedes, BMW and Lexus are equipped with radar, cameras and other sensors that allow for ... features like automatic cruise control, automatic parking, lane keeping and automatic braking," and many more car manufacturers are expected to release similar features on their models in the very near future. ${ }^{5}$ The 2015 Infiniti Q50S, for instance, has "Active Land Control and lane departure features ... and Direct Adaptive Steering" that allow the driver to remove his or her hands from the steering wheel and feet from the pedals while the car is in motion. ${ }^{6}$ Similarly, the 2015 Mercedes-Benz S65 AMG offers "Distrionic Plus with Steering and Active Lane-Keeping Assist," and the 2016 BMW 750i xDrive offers "Active Driving Assistant Plus" that does essentially the same things. All of these models and systems raise the same concern: that drivers of these vehicles will overestimate the safety of their car's semi-autonomous capabilities while simultaneously underestimating their need to monitor the vehicle.

5. Andrew Connor, Semi-Autonomous Cars Bring the Self-Driving Car Closer to Reality, GEAR PATROL (Oct. 23, 2015), http://gearpatrol.com/2015/10/23/semi-autonomous-carsbring-self-driving-car-closer-reality [https://perma.cc/7AEN-2EN4].

6. Don Sherman, 2015 Infiniti Q50S, CAR \& DRIVER (Feb. 2016), http:// www.caranddriver.com/features/semi-autonomous-cars-compared-tesla-vs-bmw-mercedesand-infiniti-feature-2015-infiniti-q50s-page-2 [https://perma.cc/LH5Y-DQUX].

7. Don Sherman, 2015 Mercedes-Benz S65 AMG, CAR \& DrIVER (Feb. 2016), https:// www.caranddriver.com/features/semi-autonomous-cars-compared-tesla-vs-bmw-mercedesand-infiniti-feature-2015-mercedes-benz-s65-amg-page-3 [https://perma.cc/SYN4-JXWB].

8. Don Sherman, 2016 BMW 750i xDrive, CAR \& DRIVER (Feb. 2016), https:// www.caranddriver.com/features/semi-autonomous-cars-compared-tesla-vs-bmw-mercedesand-infiniti-feature-2016-bmw-750i-xdrive-page-4 [https://perma.cc/VSS3-7RMF]. 
Despite these concerns, U.S. lawmakers have done virtually nothing to regulate or even investigate semi-autonomous cars. Instead, they have focused their efforts on the fully driverless cars that are not yet available to consumers, rather than the partially driverless cars that are already on U.S. roads. Indeed, the September 2016 Federal Automated Vehicles Policy ("Policy") released by the National Highway Traffic Safety Administration (NHTSA) explicitly states that it only applies to "highly" automated vehicles and does virtually nothing to ensure the safety of semiautonomous cars. ${ }^{9}$ This oversight has been a grave mistake. A growing body of research shows that drivers have an extremely difficult time adequately monitoring semi-autonomous cars, and yet growing numbers of these vehicles are sold in this country each year. As a result, lawmakers should worry that the United States could experience an uptick in highway injuries and fatalities in the very near future unless federal and state governments step in to regulate both the design and use of these cars in a comprehensive yet sensible manner. Worse yet, such an uptick in traffic accidents could stymie the development and adoption of fully autonomous cars which, counterintuitively, will almost certainly be significantly safer than their semi-autonomous counterparts.

In this paper, I explore the ways in which existing driverless car laws and policy initiatives have not adequately dealt with the risks posed by semi-autonomous cars. In particular, I focus on the limitations of the Policy, a document which will likely be extremely influential in the development of driverless car law at both the federal and state levels in coming years. I then advocate for a series of laws designed to fill the gap in driverless car regulation and minimize the inherent risks of semi-autonomous vehicles. I conclude by noting that, because semi-autonomous cars pose an entirely different set of safety concerns and considerations than fully autonomous ones, we should be careful to consider each type of car on its own merits rather than responding to all levels of automation with lowest common denominator policies and laws.

In Part I of this paper, I describe the development of driverless car technology in the United States, the levels of automation that the NHTSA has established to describe the differences in those technologies, and the benefits that consumer adoption of driverless cars will likely provide to the United States. In Part II, I provide an overview of the state of the law - both federal and state - surrounding the development and use of driverless cars. In Part III, I analyze the risks presented by semiautonomous cars, vehicles that require constant monitoring by human drivers while their automated features are engaged. Namely, I discuss the issues with both driver distraction and consumer misconceptions about the aptitudes and limits of these automated features. In Parts IV and V, I argue that a series of changes need to be made to federal and state law to address these issues. Each of these changes, I posit, is a necessary component of both enhancing highway safety in the United States and promoting the use and development of safer automobiles. I conclude by discussing additional research and analysis that need to occur in this area of the law.

9. Nat'l Highway Traffic Safety Admin., Federal Automated Vehicles Policy 10 (2016), https://www.transportation.gov/sites/dot.gov/files/docs/AV\%20policy\%20 guidance\%20PDF.pdf [https://perma.cc/KYP8-G4LW]. 


\section{BACKGROUND}

Driverless cars, or "autonomous vehicles" as they are known in both law and academic literature, "are those in which at least some aspects of safety-critical control function (e.g., steering, throttle, or braking) occur without direct driver input."10 These vehicles use a combination of sensors - including radar systems, cameras, lasers, and global positioning system (GPS) units - to gather real-time information about the vehicle's surroundings and to assess important variables such as vehicle position, speed, location, and the speed and location of other vehicles, objects, and people nearby. ${ }^{11}$

\section{A. Levels of Automation}

The degree to which a driverless car can function independently of a human driver depends upon its level of automation. In the 2016 Policy, NHTSA adopted the sixlevel measurement of automation created by SAE International, a professional association of automotive engineers. ${ }^{12} \mathrm{SAE}$ created these levels to provide "common terminology for automated driving," and to highlight the differences between semi-autonomous and fully autonomous cars. ${ }^{13}$ NHTSA believes that adopting these levels and SAE's definitions thereof will provide both "clarity and consistency" in discussions about automated vehicles. ${ }^{14}$ Those levels are as follows:

Level 0 - No Automation: In Level 0 vehicles, a human driver "does everything." 15 The driver must steer the vehicle, accelerate, brake, use appropriate signals, and monitor both the vehicle and the road at all times. ${ }^{16}$ An older car without cruise control is an example of a Level 0 vehicle.

Level 1-Driver Assistance: Level 1 vehicles contain "an automated system ... [that] can sometimes assist the human driver conduct some parts of the driving task." ${ }^{17}$ In a car with a basic cruise control feature, for instance, the driver can remove his or her foot from the accelerator but must still steer the vehicle and brake if necessary. Other Level 1 cars may have an automated system like electronic stability control that may operate in the "background" and assist the driver in avoiding accidents but otherwise not assist the driver with any parts of his or her moment-bymoment driving tasks. In short, in Level 1 vehicles, "there is no combination of

10. Nat'l Highway Traffic Safety Admin., Preliminary Statement of Policy CONCERNing AutomAted VeHICles 3 (2013) http://www.nhtsa.gov/staticfiles/ rulemaking/pdf/Automated_Vehicles_Policy.pdf [https://perma.cc/C54U-8JCN].

11. Kyle L. Barringer, Comment, Code Bound and Down ... A Long Way To Go and a Short Time To Get There: Autonomous Vehicle Legislation in Illinois, 38 S. ILL. U. L.J. 121, 123 (2013).

12. NAt'l Highway Traffic SAFETy Admin., supra note 9, at 9.

13. SAE InT'L, Automated Driving: LeVEls of Driving Automation ARE Defined in New SAE INTERNATIONAL STANDARD J3016, at 1 (2014), https://cdn.oemoffhighway.com/files/ base/acbm/ooh/document/2016/03/automated_driving.pdf [https://perma.cc/YWX2-UF3N].

14. NAT'L Highway Traffic SAFETy Admin., supra note 9, at 9.

15. Id.

16. SAE INT'L, supra note 13 , at 2.

17. Nat'l Highway Traffic Safety Admin., supra note 9, at 9 (emphasis in original). 
vehicle control systems working in unison that enables the driver to be disengaged from physically operating the vehicle by having his or her hands off the steering wheel and feet off the pedals at the same time." 18

Level 2-Partial Automation: In Level 2 cars, "an automated system on the vehicle can actually conduct some parts of the driving task, while the human continues to monitor the driving environment and performs the rest of the driving task." 19 "Combined functionality" is the hallmark of Level 2 vehicles. ${ }^{20}$ The driver may engage in a combination of automated features - cruise control and lane centering, for instance - that allow him or her to cede more than one driving function to the vehicle itself. A driver of a Level 2 vehicle, for instance, may be able to remove his or her hands from the steering wheel and foot off the pedals at the same time. ${ }^{21}$ However, because the vehicle is not fully automated, the driver "is still responsible for monitoring the roadway ... and is expected to be available for control at all times and on short notice." 22

Level 3-Conditional Automation: Level 3 vehicles have automated systems that "can both actually conduct some parts of the driving task and monitor the driving environment in some instances, but the human driver must be ready to take back control when the automated system requests." ${ }^{23}$ The key difference between a Level 2 and a Level 3 vehicle is the level of monitoring required by the human driver. In Level 3 vehicles, the driver need only be available for "occasional control": when the vehicle signals to the driver that he or she must reassume control due to, for instance, changes in the traffic or weather patterns near the vehicle. ${ }^{24}$ Otherwise, the vehicle itself is capable of operating safely without human supervision within certain parameters, and the driver could read or text as long as he or she remained available to resume control of the vehicle when signaled to do so. ${ }^{25}$ In Level 2 vehicles, however, a human must monitor the vehicle at all times, as the vehicle's ability to detect what is happening in the environment around it is much more limited. ${ }^{26}$

Level 4-High Automation: In Level 4 vehicles, "an automated system can conduct the driving task and monitor the driving environment, and the human need not take back control, but the automated system can operate only in certain environments and under certain conditions." ${ }^{, 27}$ Unlike the drivers of Level 3 vehicles, the drivers of Level 4 vehicles are "not expected to be available for control at any time during the trip," beyond engaging the vehicle and inputting a destination. ${ }^{28}$ However, Level 4

18. Nat'L Highway Traffic Safety Admin., supra note 10, at 4.

19. NAT'L Highway TrafFic SAFETy Admin., supra note 9, at 9 (emphasis in original).

20. NAT'L Highway TrafFic SAFETy Admin., supra note 10, at 5.

21. Id.

22. $I d$.

23. NAt'L Highway Traffic SAFEty Admin., supra note 9, at 9 (emphasis in original).

24. NAT'L Highway TrafFiC SAFETy Admin., supra note 10, at 5.

25. Nat'l Highway Traffic Safety Admin., Report No. DOT HS 812 044, Human Factors Evaluation of Level 2 and Level 3 Automated Driving Concepts: Concepts OF OPERATION 26 (2014).

26. See id.

27. NAT'L Highway TrafFic SAFETy Admin., supra note 9, at 9.

28. NAT'L Highway TrafFic SAFETy Admin., supra note 10, at 5. 
vehicles can only be operated safely "in certain environments and under certain conditions," like the absence of severe weather. ${ }^{29}$ The difference between Level 3 and Level 4 vehicles is essentially one of degree: Level 4 vehicles can drive themselves completely independently in a greater number of conditions and circumstances.

Level 5-Full Automation: In Level 5 automobiles, "the automated system can perform all driving tasks, under all conditions that a human driver could perform them. ${ }^{30}$ A human driver need never supervise or control the vehicle and may, in fact, not have the option to do the latter. Some manufacturer designs for Level 5 vehicles, for instance, lack steering wheels and pedals.

In this article, I will be focusing on Level 2 autonomous vehicles: those that are partially driverless, or "semi-autonomous" (I will be using those terms interchangeably). These vehicles, as noted above, can conduct some aspects of driving for the driver, but require constant human supervision for safe operation. As discussed at length below, this need for human supervision makes these vehicles very different than highly automated vehicles (HAVs), those that are Level 3 or higher and require only limited supervision or no supervision at all.

\section{B. The Development of Driverless Cars}

As of mid-2018, Level 0, 1, and 2 vehicles are available for consumer purchase and are legal to drive in every state. While it is difficult to find precise numbers, it appears that the overwhelming majority of cars currently on U.S. roads fall into the first two categories, containing either extremely little or no automation capabilities. Level 2 cars are currently available, but seem to make up a low percentage of the over 250 million vehicles in the United States, ${ }^{31}$ with their number likely hovering somewhere between 90,000 and $200,000 .^{32}$ That percentage, however, is expected to change quickly.

A significant number of major vehicle manufacturers have either already released or plan to release a Level 2 automation system into at least some of their models within the next twelve months. Models offered by Mercedes, Infiniti, BMW, Audi, and Lexus are already "equipped with radar, cameras and other sensors that allow for safety and convenience features like automatic cruise control, automatic parking, lane keeping and automatic braking." ${ }^{33}$ Additionally, in late 2017, Cadillac debuted its "Super Cruise" system, which works much like Tesla's Autopilot, on its 2018

29. Nat'l Highway Traffic SAfety Admin., supra note 9, at 9.

30. Id.

31. Number of Vehicles Registered in the United States from 1990 to 2016 (in 1,000s), STATISTA, https://www.statista.com/statistics/183505/number-of-vehicles-in-the-united-statessince-1990 [https://perma.cc/6GDS-Y2YT].

32. An August 2016 article, for instance, notes that there were over 90,000 Autopilotenabled Teslas in the United States at that time. Since that time, Tesla has released its Autopilot 2.0 and other car manufacturers have released their partially autonomous systems, so that number has likely increased substantially. Jack Stewart, Tesla's Cars Have Driven Over 140M Miles on Autopilot. Here's How, WIRED (Aug. 17, 2016, 8:00 AM), https://www.wired.com/2016/08/how-tesla-autopilot-works [https://perma.cc/CE3M-35ST].

33. Connor, supra note 5. 
Cadillac CT6 model. ${ }^{34}$ Honda has also said that it expects to release semi-autonomous technologies into its models fairly soon. ${ }^{35}$

Experts expect that more advanced HAVs will be available for purchase within less than five years. Tesla, for instance, has asserted that its Model S is likely to be fully driverless (either Level 4 or 5) by the end of 2018. More conservative industry experts expect other fully autonomous Level 4 or 5 vehicles to be available for consumer purchase by $2019 .{ }^{36}$ Ford and Google, for instance, are both actively designing and testing models that lack a steering wheel, accelerator, and brake pedals. ${ }^{37}$ While there is a fairly steady trickle of news articles and commentary asserting that fully driverless cars are much further off than industry insiders have predicted, ${ }^{38}$ if anything, "[s]elf-driving technology has developed far faster than experts envisioned when Google started developing it in 2009."39 Thus, industry insiders predict that approximately seventy-five percent of vehicles on U.S. roads will be fully autonomous by $2035 .^{40}$

Where automakers differ is in their approach to the development of autonomous vehicles. ${ }^{41}$ Manufacturers and technology companies are taking one of two approaches. First, most traditional automobile manufacturers are taking a "gradualist"

34. John R. Quain, Hands-Free Caddy: 2018 Cadillac CT6 Launches Super Cruise SemiAutonomous Feature, CAR \& DRIVER (Sept. 26, 2017, 3:59 PM), https:/www.caranddriver.com/news/hands-free-caddy-2018-cadillac-ct6-launches-supercruise-semi-autonomous-feature [https://perma.cc/7DJ7-KCKH].

35. Sam Byford, Honda Reveals Its Plans for Autonomous Vehicles, Verge (June 8, 2017, 8:02 AM), https://www.theverge.com/2017/6/8/15761272/honda-self-driving-carsautonomous-level-4-date [https://perma.cc/Z57R-3FEC].

36. Trefis Team, General Motors Inching Closer to Self-Driving Cars, ForBEs (Mar. 16, 2016, 8:38 AM), http://www.forbes.com/sites/greatspeculations/2016/03/16/general-motorsinching-closer-to-self-driving-cars [https://perma.cc/E9JH-8XRV].

37. For information on Ford's self-driving car, see Mike Murphy, Ford (F) Will Have a Self-Driving Car with No Steering Wheels or Pedals in 2021, QuARTZ (Aug. 16, 2016), https://qz.com/759643/ford-self-driving-car-2012-no-steering-wheels-or-pedals-or-handoverfunction [https://perma.cc/DS55-XDPH]. For information on Google's, see Samuel Gibbs, Google's Self-Driving Car: How Does It Work and When Can We Drive One?, Guardian (May 29, 2014, 12:11 PM), https://www.theguardian.com/technology/2014/may/28/googleself-driving-car-how-does-it-work [https://perma.cc/QX8G-YM8X].

38. See Scott Collie, DMV Report Shows Self-Driving Cars Are Learning — Fast, New ATLAS (Feb. 2, 2017), http://newatlas.com/google-waymo-dmv-disengagements-report/47716 [https://perma.cc/VKS4-NGEG]; Connor, supra note 5; Lauren Johnson, Automakers Are Improving Self-Driving Cars with Troves of Data, ADWEEK (Feb. 28, 2017), $\mathrm{http} / /$ www.adweek.com/digital/automakers-are-improving-self-driving-cars-with-troves-of-data [https://perma.cc/BYF3-87QQ].

39. Paul Ingrassia, Alexandria Sage \& David Shepardson, How Google Is Shaping the Rules of the Driverless Road, Reuters: Investigates (Apr. 26, 2016, 12:30 PM), http:// www.reuters.com/investigates/special-report/autos-driverless [https://perma.cc/6J2D-QM9W].

40. Richard C. Balough, Are Your Clients Ready for the Impact of Driverless Cars?, Bus. L. Today, May 2016, at 1, 2; Noah Buhayar \& Peter Robison, Can the Insurance Industry Survive Driverless Cars?, BloOMBerg Businessweek (July 30, 2015, 4:00 AM), http://www.bloomberg.com/news/articles/2015-07-30/can-the-insurance-industry-survivedriverless-cars- [https://perma.cc/7X3U-X8SC].

41. Tracy Hresko Pearl, Fast \& Furious: The Misregulation of Driverless Cars, 73 
approach to automated technologies, increasing the level of automation in their cars over time. Over the next two or three years, for instance, they will sell Level 2 vehicles while continuing to pursue the goal of producing Level 4 or 5 vehicles five years from now. ${ }^{42}$ This slower approach to development gives consumers time to grow "comfortable with the technology" and companies time to develop more advanced autonomous systems for later release. ${ }^{43}$

Second, tech companies, like Google, and a very small number of traditional automobile manufacturers are taking an "all-in" approach to driverless cars, developing and testing fully driverless Level 4 or 5 vehicles immediately and not releasing them to consumers until they are certain the vehicles can drive safely with no human intervention or supervision. ${ }^{44}$ Companies taking this more aggressive approach are doing so out of concern for consumer safety; they wish to avoid Level 2 and even Level 3 vehicles because these vehicles present "one of the biggest challenges with this technology: [h] ow to safely transfer control from the computer to the driver, particularly in an emergency." ${ }^{45}$ Ford, for instance, has said that it does not believe that a "quick handoff" from vehicle to driver is feasible. ${ }^{46}$ Google has gone even further, asserting that any human involvement would make their driverless cars "less safe." 47

The dominant approach, thus far, has been a gradualist approach ${ }^{48}$ As discussed above, a large number of automobile manufacturers have either already released Level 2 versions of their vehicles or are planning to do so within a matter of months. As one journalist has observed, this is a "faster and cheaper" approach to entering into the market for driverless cars. ${ }^{49} \mathrm{It}$ is also, he notes, a way to enhance their bottom line: "[f]eatures such as collision-avoidance radar, self-steering and self-parking boost profit per vehicle" and allow companies to capture this revenue immediately rather than waiting until their Level 4 or 5 vehicles have been fully developed. ${ }^{50}$

N.Y.U. AnN. SuRV. Am. L. 19, 30-34 (2017).

42. Justin Pritchard, How Can People Safely Take Control from a Self-Driving Car, Associated Press, (Nov. 30, 2015), https://apnews.com/84c6f179beb24f758a40acac1340ce78 [https://perma.cc/KAU8-PP3W].

43. Henry Fountain, Yes, Driverless Cars Know the Way to San Jose, N.Y. Times (Oct. 26, 2012), http://www.nytimes.com/2012/10/28/automobiles/yes-driverless-cars-know-theway-to-san-jose.html [https://perma.cc/6FMQ-K7KK]; see also Ingrassia et al., supra note 39 ("Ford Motor is developing both L3 cars and L4 cars, says Ken Washington, vice president for research and advanced engineering. But Ford prefers L4 technology because, like Google, it doesn't think a quick handoff from machine to human is feasible.").

44. Ford Motor Co., Comment Letter on Federal Automated Vehicle Policy (Nov. 22, 2016), https://www.regulations.gov/document?D=NHTSA-2016-0090-1128 [https://perma.cc/ EC4X-AEXE]; Alex Davies, Google's Self-Driving Car Hits Roads Next Month-Without a Wheel or Pedals, WiRED (Dec. 23, 2014, 1:24 PM), http:/www.wired.com/2014/12/googleself-driving-car-prototype-2 [https://perma.cc/2JD8-AS5B].

45. Alex Davies, Ford's Skipping the Trickiest Thing About Self-Driving Cars, WIRED (Nov. 10, 2015, 7:00 AM), https://www.wired.com/2015/11/ford-self-driving-car-plan-google [https://perma.cc/4AVK-WM6D].

46. Ingrassia et al., supra note 39.

47. Pritchard, supra note 42.

48. Ingrassia et al., supra note 39.

49. Id.

50. Id. 


\section{Benefits of Driverless Cars}

The development of driverless cars is likely to yield tremendous benefits for society as they "are now poised to be the next great transformative transportation technology ... [and] are predicted to have a significant impact on how we live, work, and use our time. ${ }^{, 51}$ Among a number of significant benefits, they are likely to reduce traffic, increase productivity, enhance fuel efficiency, and provide greater transportation accessibility to groups like the elderly and the disabled whose members may be unable to qualify for a driver's license.$^{52}$ Most importantly, fully driverless cars will likely reduce traffic accident injuries and fatalities by a significant percentage..$^{53}$

Automobile accidents in the United States injure and kill shocking numbers of people. Each day, an average of 100 people are killed on U.S. roads and 6000 more are injured. ${ }^{54}$ While traffic accidents have generally been on the decline for the past decade, a recent NHTSA study showed a troubling reversal of that trend:

A statistical projection of traffic fatalities for 2016 shows that an estimated 37,500 people died in motor vehicle crashes. This represents an increase of about 6.9 percent as compared to the 35,092 fatalities reported to have occurred in 2015 . . . If these projections are realized, fatalities will be at the highest level since 2007 when 41,259 fatalities were reported ... The fourth quarter of 2016 represents the ninth consecutive quarter with year-to-year increases in fatalities as well as the fatality rate. ${ }^{55}$

Even before this uptick, motor vehicle crashes were the leading cause of death for several different age groups in this country ${ }^{56}$ and the economic cost of motor vehicle crashes exceeded $\$ 240$ billion each year. ${ }^{57}$

Human drivers are overwhelmingly the cause of these accidents. ${ }^{58}$ Studies consistently show that approximately ninety-four percent of all traffic accidents are

51. Leili Fatehi \& Frank Douma, Autonomous Vehicles: The Legal and Policy Road Ahead, 16 Minn. J.L. ScI. \& TeCH. 615, 617 (2015).

52. Frank Douma \& Sarah Aue Palodichuk, Criminal Liability Issues Created by Autonomous Vehicles, 52 SAnta Clara L. ReV. 1157, 1158 (2012).

53. See infra notes 54-62.

54. Adam Thierer \& Ryan Hagemann, Removing Roadblocks to Intelligent Vehicles and Driverless Cars, 5 WAKE Forest J.L. \& POL'y 339, 350-51 (2015).

55. Nat'l Highway Traffic Safety Admin., DOT HS 812 401, Early Estimate of Motor Vehicle Traffic Fatalities in 2016, at 1 (2017), https:/crashstats.nhtsa.dot.gov/ Api/Public/ViewPublication/812401 [https://perma.cc/7RC6-E7QH].

56. Nat'l Highway Traffic Safety Admin., DOT HS 812 263, Summary of Motor Vehicle Crashes (FInAL) 1 (2016), http://www-nrd.nhtsa.dot.gov/Pubs/812263.pdf [https:// perma.cc/6DYG-74QC].

57. Id. at 3 .

58. Carrie Schroll, Splitting the Bill: Creating a National Car Insurance Fund To Pay for Accidents in Autonomous Vehicles, 109 Nw. U. L. REV. 803, 807 (2015); Barringer, supra note 11, at 137. 
caused by human driver error rather than vehicle malfunction or nature-related phenomena (weather, animals on the road, etc.). ${ }^{59}$ Drunk driving accounts for a startlingly large portion of these accidents, causing approximately thirty-one percent of all traffic-related fatalities. ${ }^{60}$ Additionally, distracted driving-driving while talking on the phone, texting, or using other electronic devices-is a growing problem on U.S. roads. One study revealed that seven in ten American drivers said "that as a result of being distracted while driving, they have slammed their brakes or swerved to avoid an accident, missed a traffic signal, or actually caused an accident.." ${ }^{11}$ Another study revealed that "[m]ore than half of all eighteen-to-twenty-fouryear-olds admit to texting while driving, and more than eighty percent drive while on the phone." ${ }^{\prime 62}$ There are also other common driver issues that contribute to the likelihood of traffic accidents: driving while drowsy, making errors of judgment, failing to react to evolving driving situations quickly enough, and speeding.

By taking humans out of the driver's seat, fully autonomous vehicles (Levels 4 or 5) can eliminate all of these problems. Not only are they incapable of driving drunk, their powers of perception are significantly better than those of humans: "Autonomous vehicles, powered by sensors, software, cartography, and computers, can build a real-time model of the dynamic world around them and react appropriately. Unlike human drivers, they do not get distracted or tired, have almost instantaneous perception-reaction times, and know exactly how hard to brake or when to swerve." 63

Thus, experts have predicted that "if 10 percent of vehicles in use were autonomous vehicles, 1,100 fewer people would die in car accidents. 'With 90 [percent] penetration, the U.S. would save 21,700 lives and have 4.2 million fewer crashes per year." ${ }^{64}$ These safety gains alone should be enough to convince U.S. policymakers to strongly support and promote the development of these vehicles.

\section{CURRENT LAWS \& Policies}

Both state and federal lawmakers have begun to prepare in earnest for the coming influx of autonomous cars on U.S. roads. These vehicles will not only revolutionize

59. Schroll, supra note 58, at 805 .

60. Nat'l Highway Traffic Safety Admin., DOT HS 812 231, Alcohol-ImPaired DRIVING 1 (2015), http://www-nrd.nhtsa.dot.gov/Pubs/812231.pdf [https://perma.cc/XA3EWL9G].

61. Allstate, New Allstate Survey Shows Americans Think They are Great Drivers Habits Tell a Different Story, PR Newswire (Aug. 2, 2011, 1:00 PM), $\mathrm{http} / /$ www.prnewswire.com/news-releases/new-allstate-survey-shows-americans-think-they-aregreat-drivers---habits-tell-a-different-story-126563103.html [https://perma.cc/8LYP-2EVG].

62. Burkhard Bilger, Auto Correct: Has the Self-Driving Car at Last Arrived?, New YORKER (Nov. 25, 2013), https://www.newyorker.com/magazine/2013/11/25/auto-correct [https://perma.cc/US3F-3YY7].

63. David Levinson, Climbing Mount Next: The Effects of Autonomous Vehicles on Society, 16 MinN. J.L. SCI. \& TECH. 787, 795 (2015).

64. Jeffrey K. Gurney, Driving into the Unknown: Examining the Crossroads of Criminal Law and Autonomous Vehicles, 5 WAKE FOREST J.L. \& POL'Y 393, 402 (2015) (alteration in original) (quoting Neal Katyal, Disruptive Technologies and the Law, 102 GEO. L.J. 1685, 1688 (2014)). 
driving, they will also require significant changes to existing motor vehicle laws and policies, if not an overhaul those laws altogether:

While there is already a robust body of laws pertaining to automotive and highway safety, there also seems to be consensus that those laws must be amended because they are all based on the underlying assumption that human beings are operating the vehicle. Furthermore, given that autonomous technology innovations are 'severely outpacing legislation designed to allows for [their] use,' lawmakers appear to be feeling some urgency to make those amendments or at least pass some semblance of a framework of laws pertaining to driverless cars. ${ }^{65}$

Tech companies and automobile manufacturers appear to feel the same sense of urgency and are actively calling for federal and state lawmakers to develop a comprehensive legal scheme for fully autonomous vehicles as quickly as possible. ${ }^{66}$ Indeed, because fully autonomous vehicles must be programmed by manufacturers to obey traffic and motor vehicle laws, (a) manufacturers must know what those laws are in advance of releasing their vehicles to the general public, and (b) those laws must be applicable to both human-driven and autonomous cars. For instance, laws like the one currently in force in New York that require drivers to keep one hand on the steering wheel at all times would presumably make it illegal for humans to ride in a Level 5 vehicle that lacks a steering wheel altogether. ${ }^{67}$

\section{A. State Driverless Car Laws}

State lawmakers have taken the lead on making these changes and additions to motor vehicle laws. ${ }^{68}$ As of May 2018, twenty states have enacted or adopted laws pertaining to driverless cars, ${ }^{69}$ another six have driverless car legislation pending, ${ }^{70}$

65. Pearl, supra note 41, at 43 (alteration in original) (quoting Marcus E. Johnson, The Drive for Autonomous Vehicles: Idaho's Race To Catch Up, 59 ADVoc. 28, 28 (2016)).

66. See Alex Davies, The Feds Will Have Rules for Self-Driving Cars in the Next 6 Months, Wired (Jan. 14, 2016, 1:40 PM), https://www.wired.com/2016/01/the-feds-wantrules-for-self-driving-cars-in-the-next-6-months [https://perma.cc/RQ9N-GA4D]; Laura Putre, Volvo CEO Weighs in on Self-Driving Regulation, INDUSTRY WK. (Oct. 9, 2015), http://www.industryweek.com/regulations/speed-self-driving-regulation-says-volvo-ceo [https://perma.cc/UT38-NJTA].

67. Bryant Walker Smith, Automated Vehicles Are Probably Legal in the United States, 1 Tex. A\&M L. Rev. 411, 413 (2014) (citing N.Y. VeH. \& Traf. LAW $§ 375$ (McKinney 2013)); see also Andrew Dalton, A 45-Year-Old New York Law Is Holding Up Autonomous Vehicles, ENGADGET (May 31, 2016), https://www.engadget.com/2016/05/31/new-york-lawholding-up-autonomous-vehicles [https://perma.cc/XQ6C-V7DX].

68. See John Frank Weaver, Robots Are People Too: How Siri, Google Car, and Artificial Intelligence Will Force Us To Change Our Laws 55 (2014).

69. See, e.g., CaL. Veh. Code $§ 38750$ (West Supp. 2018); D.C. Code § 50-2352 (2014); Fla. Stat. AnN. §316.86 (West Supp. 2018); Mich. Comp. LaWs AnN. §257.665 (West Supp. 2017); Nev. Rev. Stat. AnN. § 482A.100 (LexisNexis Supp. 2016).

70. Autonomous Vehicles Legislation Database, NAT'L CONF. OF StATE Legislatures (May 31, 2018), http://www.ncsl.org/research/transportation/autonomous-vehicles-legislativedatabase.aspx [https://perma.cc/TSP5-LYQR]. 
and two states have contemplated — but failed — to pass such laws. ${ }^{71}$ Although each state statute is somewhat unique, similar types of provisions exist within them. For example, at least three states have passed driverless car laws that define the person who engages a driverless car (i.e., turns on its engine) as the "operator" of that vehicle. ${ }^{72}$ Similarly, four states and the District of Columbia have passed laws that would require human drivers to "override," or retake control, of their autonomous vehicles under certain circumstances. ${ }^{73}$

In my earlier work, I have detailed both the content of existing state laws and the ways in which those laws manage to be both overbroad and unduly narrow. ${ }^{74}$ Namely, existing state driverless car laws ignore the differences between semi-autonomous and fully autonomous vehicles, impose unwarranted liability on human drivers in many circumstances, and incentivize human driver behavior that may be less safe than letting the autonomous vehicles drive themselves. ${ }^{75} \mathrm{I}$ have also posited that the legal issues created by these driverless car laws could chill the development and production of these vehicles. ${ }^{76}$

Tech companies and automobile manufacturers have expressed similar concerns and cast a proverbial wary eye on the lead that states have taken over the federal government in their driverless car-related lawmaking efforts. Indeed, "[a]s growing numbers of states pass 'a patchwork of rules' pertaining to driverless cars, industry officials have grown concerned about inconsistencies between those rules and about their ability to manufacture autonomous vehicles that will comply with the laws of all fifty states." ${ }^{177}$ Companies ranging from Google to General Motors have urged Congress to make the federal government the locus of control of regulation of autonomous vehicles. ${ }^{78}$ In 2016, the Obama administration responded to these calls by both (a) proposing to spend $\$ 3.9$ billion over the next ten years to promote the development of driverless cars and supporting infrastructure and (b) ordering the U.S. Department of Transportation (DOT) to draft a comprehensive driverless car policy within six months. ${ }^{79}$ The DOT's response arrived in the form of the Federal Automated Vehicle Policy, released in September of that year. ${ }^{80}$

71. Id.

72. Cal. Veh. Code $\S 38750(a)(4)$ (West Supp. 2018); Fl. Stat. Ann. § 316.85 (West Supp. 2018); NeV. Admin. Code $\S 482$ A.020 (2016).

73. CAL. Veh. Code $§ 38750$ (West Supp. 2018); D.C. Code $§ 50-2352$ (2013); Fl. STAT. AnN. § 319.145 (West Supp. 2018); Nev. Rev. Stat. § 482A.100 (LexisNexis Supp. 2016).

74. Pearl, supra note 41, at 43-67.

75. Id. at 23.

76. Id. at 71 .

77. Id. at 45 (quoting Davies, supra note 66).

78. Nathan Bomey, Self-Driving Car Leaders Ask for National Laws, USA ToDAY (Mar. 15, 2016, 10:27 PM), http://www.usatoday.com/story/money/cars/2016/03/15/googlealphabet-general-motors-lyft-senate-commerce-self-driving-cars/81818812 [https://perma.cc/ XLA3-9EKW].

79. Id.; Davies, supra note 66.

80. NAT'L Highway TrafFic SAFETy AdMin., supra note 9. 


\section{B. The Federal Automated Vehicle Policy}

On September 20, 2016, NHTSA issued the "Federal Automated Vehicles Policy" ("Policy"). ${ }^{81}$ Its stated goals were to "set[] out an ambitious approach to accelerate the [heavily automated vehicle (HAV)] revolution" by issuing "agency guidance rather than ... rulemaking in order to speed the delivery of an initial regulatory framework and best practices to guide manufacturers and other entities in the safe design, development, testing, and deployment of HAVs." ${ }^{82}$ In short, NHTSA sought to create a framework that would encourage consistency in driverless car laws across state lines while providing maximum flexibility for car manufacturers and tech companies to continue their development and testing of autonomous cars. ${ }^{83}$

Issuing policies like this one is clearly within NHTSA's scope of responsibility rather than that of any other federal agency:

Fifty years ago, Congress enacted the National Traffic and Motor Vehicle Safety Act ["Safety Act"] . . . giving NHTSA broad jurisdiction over all elements of design in motor vehicles and motor vehicle equipment. It also directed the Agency to issue Federal Motor Vehicle Safety Standards (FMVSS) ["Standards"] to reduce motor vehicle crashes and related deaths and injuries. ${ }^{84}$

It is NHTSA's difficult task, therefore, to assess whether and how automated vehicles ought to be regulated under the Safety Act and Standards, a challenging task given that automated vehicles pose very distinct - and fairly new — sets of safety risks and benefits. As NHTSA notes in the Policy:

The innovative technologies that are the basis of HAVs are vastly different from the technologies that existed when Congress enacted the Safety Act. Then, vehicles were largely mechanical and controlled by the human driver via mechanical inputs and linkages. At that time, sensing of a vehicle's performance and the roadway environment, and making driving decisions about that performance were done solely by the human driver. $^{85}$

Now, however, humans have less and less control over their vehicles as those vehicles become more automated, and NHTSA must confront these dramatic changes with virtually no guidance from existing law and policy. Indeed, existing motor vehicle laws provide virtually no guidance to NHTSA, as they are all based on the fundamental assumption that human drivers, rather than anything else, are in control of the vehicles on U.S. roads.

81. Id.

82. Id. at 6 .

83. See Nat'l Highway Traffic Safety Admin., supra note 9, at 5-10; Johnathan M. Gitlin, The Federal Self-Driving Vehicles Policy Has Finally Been Published, ARs TeCHICA (Sept. 20, 2016, 4:30 PM), https://arstechnica.com/cars/2016/09/the-federal-self-drivingvehicles-policy-has-been-finally-published [https://perma.cc/C2FD-UVUE].

84. NAT'L HighwAY TRAFFIC SAFETY AdMIN., supra note 9, at 68 (citation omitted).

85. Id. at 69 . 
NHTSA has begun what will almost certainly be a long and involved law and policy-making process by acting somewhat tentatively, repeatedly making clear that the Policy is "not mandatory," and requesting cooperation and voluntary information-sharing on the part of manufacturers. ${ }^{86}$ NHTSA also notes in the Policy that it does not, as of yet, see any need to shift the current division of responsibility between the federal government and the states with regard to regulating automobiles: "[Department of Transportation (DOT)] and the Federal Government are responsible for regulating motor vehicles and motor vehicle equipment, and States are responsible for regulating the human driver and most other aspects of motor vehicle operation." 87

Despite NHTSA's seeming hesitancy to begin imposing mandatory requirements on autonomous vehicle manufacturers and the somewhat preliminary nature of the Policy, the Policy has a number of notable features.

\section{Focus on Level 3 Vehicles and Above}

First, despite the fact that fairly significant amounts of automation are present in vehicles that qualify as Level 2 or higher, the DOT has "draw[n] a distinction between Levels 0-2 and [Levels] 3-5 [vehicles] based on whether the human operator or the automated system is primarily responsible for monitoring the driving environment." ${ }^{88}$ More notably, NHTSA notes that the Policy is only intended to apply to vehicles that are Level 3 or higher. ${ }^{89}$ The Policy is much more reticent with regard to providing guidance for Level 2 vehicles. NHTSA expresses concern about the safety of these lower level vehicles and makes several recommendations to manufacturers that are currently producing them, but otherwise does little to address the unique risks and benefits of semi-autonomous vehicles. ${ }^{90}$

NHTSA's failure to provide more comprehensive guidance with regard to Level 2 vehicles has been a common criticism in the public comments that followed the release of Policy. Delphi, a prominent tech company, expressed concern "that the Policy provides inconsistent messaging regarding NHTSA's view of SAE Level 2 vehicles and the level of compliance expected." ${ }^{\prime 91}$ Ford Motor Company stated that it "believes that further clarifications and revisions to the Guidance areas for testing for [Level 2 vehicles] need to be considered." ${ }^{22}$ The advocacy group Consumer Watchdog was troubled that the Policy "notes the importance of training HAV drivers, but sets no required standards" for educating drivers of Levels 2 vehicles "where consumers have sometimes been led to believe that the vehicle is more capable of driving itself than is actually the case. ${ }^{.93}$ Similarly, Consumer Reports noted that it

86. Id. at 11,15 .

87. Id. at 38 .

88. Id. at 10 .

89. Id.

90. See id. at $32-33$.

91. Delphi, Comment Letter on Federal Automated Vehicle Policy (Nov. 22, 2016), https:// www.regulations.gov/document?D=NHTSA-2016-0090-1053 [https://perma.cc/YJ7K-HXEB].

92. Ford Motor Co., supra note 44, at 5.

93. Consumer Watchdog, Comment Letter on Federal Automated Vehicle Policy 6 (Nov. 22, 2016), https://www.regulations.gov/document?D=NHTSA-2016-0090-1050 [https://perma.cc/ 
was concerned about "human-machine interface (HMI) factors on safety," particularly in Level 2 and 3 vehicles and that the Policy did not adequately address this issue. ${ }^{94}$ Nevertheless, as of early 2018, NHTSA has not yet released a set policy or guidance with regard to Level 2 vehicles.

\section{Lack of a Premarket Approval Process}

Second, nothing in the Policy requires tech companies or more traditional automobile manufacturers to obtain premarket approval from NHTSA before introducing new forms of automation into their vehicles. ${ }^{95}$ Instead, as long as those vehicles comply with the Federal Motor Vehicle Safety Standards (FMVSS), they may be sold to consumers without consulting with NHTSA in advance, even though the FMVSS were developed prior to the availability of semi-autonomous cars. ${ }^{96}$ NHTSA explains that creating a premarket approval process for autonomous cars is not within its current authority and thus would require a statutory change rather than a unilateral decision on the part of the agency to regulate these vehicles. ${ }^{97}$

This lack of a premarket approval process for autonomous cars is highly problematic. One journalist explains:

The National Highway Traffic Safety Administration says it lacks the authority to pre-empt automakers' new autonomous features until something goes wrong.

"If someone wants to sell a totally automated vehicle today, you could probably get a court to decide there's nothing N.H.T.S.A can do about that until it presents an unreasonable risk to safety," said an agency spokesman, Gordon Trowbridge.

Proving such an unreasonable risk to safety under the agency's mandate, he said, means citing crashes or malfunctions that have already happened. For now, that leaves a legal vacuum . . . ${ }^{98}$

Until the needed statutory changes are made, NHTSA's only means of ensuring that a vehicle's automation systems are safe prior to consumer sales are to rely on voluntary premarket reporting on the part of tech companies and manufacturers. In the Policy, therefore, NHTSA requests that "manufacturers and other entities volun-

V6CP-YQLL].

94. Consumer Reports \& Consumers Union, Comment Letter on Federal Automated Vehicle Policy 4 (Nov. 22, 2016), https://www.regulations.gov/document?D=NHTSA-20160090-1069 [https://perma.cc/Q3YL-FRRY].

95. NAT'L HighWAY TRAFFIC SAFETY ADMIN., supra note 9, at 11 ("Therefore, if a vehicle is compliant within the existing FMVSS regulatory framework and maintains a conventional vehicle design, there is currently no specific federal legal barrier to an HAV being offered for sale." (footnote omitted)).

96. Id. at 48 .

97. Id. at 75 .

98. Aaron M. Kessler, Hands-Free Cars Take Wheel, and Law Isn't Stopping Them, N.Y. TIMES (May 2, 2015), http://www.nytimes.com/2015/05/03/business/hands-free-cars-takewheel-and-law-isnt-stopping-them.html [https://perma.cc/2EA2-7PLP]. 
tarily provide [Safety Assessment] reports regarding how the [Policy] has been followed," although it notes that it may make this reporting mandatory "through a future rule making." ${ }^{\text {99 }}$ NHTSA explains that "[mandatory reporting] would require entities to submit a Safety Assessment to NHTSA's Office of the Chief Counsel for each HAV system, outlining how they are meeting this Guidance at the time they intend their product to be ready for use ... on public roads." 100

For now, however, manufacturers are free to decide whether or not to follow the Policy and submit a Safety Assessment prior to selling their automated vehicles, and there do not appear to be any consequences for choosing not to do so. ${ }^{101}$ The only potential consequences would arise, as discussed, "[if] an autonomous vehicle or other emerging automotive technology causes crashes or injuries, or has a manifested safety-related failure or defect." 102 If that occurs, NHTSA could intervene through its preexisting investigative and enforcement authority. ${ }^{103}$

\section{Model State Policy}

Third, given that one of the main purposes of the Policy was to stave off "a patchwork of inconsistent laws and regulations among the 50 States and other U.S. jurisdiction[s]," the Policy sets forth a Model State Policy. ${ }^{104}$ NHTSA makes clear, however, both that (a) it does not intend for states to codify this model policy or, in fact, any other portion of the broader Policy, ${ }^{105}$ and (b) it does not want States to regulate "the performance of HAV technology and vehicles," which currently falls under the U.S. Department of Transportation's jurisdiction. ${ }^{106}$ Moreover, seemingly in response to complaints on the parts of tech companies and automobile manufacturers, NHTSA has requested that states "evaluate their current laws and regulations to address unnecessary impediments to the safe testing, deployment, and operation of HAVs, and update references to a human driver as appropriate." 107

Some states, however, have responded to the Model State Policy in precisely the way that NHTSA has instructed them not to- by initiating legislation to codify the Model State Policy into state law:

For example, the California Department of Motor Vehicles ... published revised draft regulations for autonomous vehicles following NHTSA's release of the Policy. The draft regulations would mandate permits to test and later deploy HAVs on public roads in California, and to obtain a permit, a manufacturer would have to certify compliance with the Vehicle Performance Guidance and submit a copy of NHTSA's Safety

99. NAt'L Highway Traffic SAfety Admin., supra note 9, at 15 (emphasis added).

100. Id.

101. Law Office of Stephen E. Selander, Comment Letter on Federal Automated Vehicle Policy 2 (Nov. 22, 2016), https://www.regulations.gov/document?D=NHTSA-2016-00901114 [https://perma.cc/ZA8G-4DNX].

102. NAT'L Highway Traffic SAFETy Admin., supra note 9, at 50.

103. Id.

104. Id. at 37.

105. Id. at 11 .

106. Id. at 37 (emphasis added).

107. Id. at 39 . 
Assessment. If these draft regulations become law, a manufacturer would effectively be required to submit the Safety Assessment, because failing to do so would proscribe the manufacturer from testing or deploying HAVs on public roads in California. ${ }^{108}$

A number of public comments to the Policy assert that this kind of state action is understandable given the ambiguities of the Policy. ${ }^{109}$ Tesla points out in its public comments, for example:

Rather than discouraging states from creating new laws and regulation concerning HAVs, Tesla believes the Policy could reasonably be read as encouraging states to create them. Indeed, the Policy language is equivocal about its directive to states: "[t]he following sections describe a model regulatory framework for States that wish to regulate procedures and conditions for testing, deployment, and operation of HAVs." A model regulatory framework that is smart and light in its guiding principles can be a beneficial step toward a consistent national framework. However, by drafting a model regulatory framework, the Agency also invites the very patchwork regulation that it seeks to avoid. ${ }^{110}$

Accordingly, other public commenters have requested that NHTSA revise the Model State Policy section to "remove language which could be interpreted to invite states directly to regulate HAV systems and vehicles." 111 It remains to be seen whether NHTSA will respond to those calls or whether it will not and states continue to adopt the Model State Policy as state law.

\section{Regulatory Gap}

All told, while the release of the 2016 Policy marks the beginnings of a federal regulatory framework for autonomous vehicles, the Policy also creates a very large regulatory gap. In opting to regulate Level 3 and higher autonomous vehicles via the Policy and not to regulate Level 2s, NHTSA is tacitly choosing to regulate the fully autonomous that are still at least a year away from market release rather than the semi-autonomous cars that are already available to consumers and on U.S. roads.

108. Tesla Motors, Inc., Comment Letter on Federal Automated Vehicle Policy (Nov. 22, 2016), https://www.regulations.gov/document?D=NHTSA-2016-0090-1051 [https://perma.cc/ Y999-923Y].

109. Id.; Google, Comment Letter on Federal Automated Vehicle Policy 1 (Nov. 22, 2016), https://www.regulations.gov/document?D=NHTSA-2016-0090-1102 [https://perma.cc/5HXPNTMU]; Continental, Comment Letter on Federal Automated Vehicle Policy 6 (Nov. 22, 2016), https://www.regulations.gov/document?D=NHTSA-2016-0090-1104 [https://perma.cc/ K5YD-2SZU]; Mercedes-Benz, Comment Letter on Federal Automated Vehicle Policy 1-2 (Nov. 22, 2016), https://www.regulations.gov/document?D=NHTSA-2016-0090-1041 [https://perma.cc/UAW9-8LMU].

110. Tesla Motors, Inc., supra note 108, at 3 (quoting NAT'L Highway Traffic SAFETY Admin., supra note 9, at 39).

111. Google, supra note 109. 
This is a critical mistake. As discussed at length below, a significant amount of evidence suggests that Level 2 vehicles are likely far more dangerous than Level 3, 4, or 5 vehicles, and thus in greater need of regulation at both the federal and state levels. ${ }^{12}$

Additionally, because Level 2 vehicles are fundamentally different than Level 3 or higher vehicles (a difference recognized by NHTSA itself in the Policy), they are in need of a different kind of regulation, a need that has thus far gone unmet by both states and the federal government. ${ }^{113}$ Because Level 2 vehicles are still human-driven cars, issues like driver distraction and consumer perceptions of the capabilities of the vehicle's automation systems are far more critical in those vehicles than in Level 3 vehicles. Those issues are not relevant at all in Level 4 and 5 vehicles. ${ }^{114}$ Thus, Level 2 vehicles, though semi-autonomous, should be regulated differently than fully autonomous vehicles so as not to blur these important distinctions. ${ }^{115}$

\section{The DANGERS OF SEMI-Autonomous CARS}

An exploration of the dangers unique to Level 2 vehicles highlights why the regulatory gap discussed immediately above ought to be addressed and corrected as quickly as possible.

\section{A. Distraction Issues}

First, despite the fact that Level 2 vehicles require continuous monitoring on the part of human drivers to ensure safe operation, ${ }^{116}$ a growing body of research shows that drivers have a difficult time maintaining focus on the vehicle and the road while using the autonomous features of these vehicles. ${ }^{117}$ In one study, human drivers were asked to sit behind the wheel of a Level 2 vehicle for between forty-five minutes and one hour and monitor the vehicle constantly while it drove down a test track with both adaptive cruise control (ACC) and lane centering (LAADS) features engaged, meaning that the test drivers did not have to steer, accelerate, or brake. ${ }^{18}$ The human drivers merely had to sit in the driver's seat and watch the road. ${ }^{119}$ Despite the simplicity of the task, their performance was poor:

112. See infra Part III.

113. FAVP, supra note 6 , at 10.

114. See Delphi, supra note 91; Consumer Watchdog, supra note 93.

115. Consumer Watchdog, supra note 93, at 11-12.

116. Jack Karsten \& Darrell M. West, Semi-Autonomous Vehicles Must Watch the Road and the Driver, BROOKINGS: TECHTANK (Jan. 30, 2017), https:/www.brookings.edu/blog/techtank/2017/01/ 30/semi-autonomous-vehicles-must-watch-the-road-and-the-driver [https://perma.cc/NLP2-BSGL].

117. See, e.g., Robert E. Llaneras, Jeremy Salinger \& Charles A. Green, Human Factors Issues Associated with Limited Ability Autonomous Driving Systems: Drivers' Allocation of Visual Attention to the Forward Roadway, Presentation, 7th Int'l Driving Symposium on Human Factors in Driver Assessment, Training \& Vehicle Design (June 17-20, 2013), http://drivingassessment.uiowa.edu/sites/default/files/DA2013/Papers/015_Llaneras_0.pdf [https://perma.cc/MH4V-VQEG].

118. Id. at 94 .

119. Id. 
Overall, drivers were estimated to be looking away from the forward roadway approximately $33 \%$ of the time .... Comparisons between ACC and LAADS head pose data reveal a significant increase in time spent looking away from the forward roadway under semi-autonomous relative to [Level 1, cruise control]-only driving ... [D]rivers tended to increase the percentage of time spent looking off-road by an average of 33 percent while driving under LAADS, suggesting that drivers were paying somewhat less attention to the forward roadway under the autonomous driving mode. This general finding is consistent with the secondary task data presented earlier suggesting that drivers engaged in more secondary activities under LAADS driving. Although this pattern was generally reliable, there were substantial individual differences in the magnitude of the effect across individuals with some drivers showing no increase under LAADS driving relative to ACC driving. Approximately one-third of the drivers (4 out of 12) showed substantial increases in the percentage of time spent looking off-road of at least $73 \%$ when operating under LAADS. ${ }^{120}$

There were also "significant increases in ... eating, reaching for an item in the rear compartment, dialing and talking on the cell phone, and texting/e-mailing," and a "widespread" increase in "very risky tasks" like reading books and watching movies while the autonomous features of these vehicles were engaged. ${ }^{121}$

A more recent study of drivers of Level 2 cars showed that drivers "exhibited significant increases in eccentric head turns [meaning simply that they turned away from the road] and secondary tasks during automated driving, even in the presence of a researcher," and that over a quarter of the drivers engaged in some form of reading while their vehicle was driving in semi-autonomous mode. ${ }^{122}$ That study concluded that while "[t]he effects of automation on a driver's attention level remains an open question ... . early research suggests that a driver cannot immediately take over control of [a semi-autonomous] vehicle safely. Most drivers will require some type of warning time." 123

Anecdotal evidence has also shown that drivers of Level 2 cars are prone to letting their attention wander. A quick tour of YouTube clips of Tesla drivers using the Autopilot features of their cars shows those drivers, among other things, sleeping, ${ }^{124}$ playing board games, ${ }^{125}$ arm wrestling, ${ }^{126}$ and, in at least one case, engaging in a plastic light saber battle. ${ }^{127}$ Google encountered similar behavior on the part of the

120. Id. at 96 .

121. Id.

122. Noah J. Goodall, Machine Ethics and Automated Vehicles, in ROAD VeHICLE Automation 93 (Gereon Meyer \& Sven Beiker eds., 2014).

123. Id.

124. Electrek.co, Tesla Model S Driver Caught Sleeping at the Wheel While on Autopilot - Electrek, YouTuBE (May 23, 2016), https://www.youtube.com/watch?v=sXls4cdEv7c [https://perma.cc/6TJF-B66T].

125. Slow News Day, Tesla's Model S Is Amazing!, YouTube (Mar. 31, 2016), https://www.youtube.com/watch?v=UgNhYGAgmZo [https://perma.cc/37WE-GQ93].

126. Jukin Media, Tesla Autopilot Road Trip, YouTuBE (June 24, 2016), https://www.youtube.com/watch?v=NqnJRo4FQNo [https://perma.cc/YH72-J7FS].

127. Id. 
test drivers of their early driverless cars who, though instructed to "watch the road at all times and be ready to retake control if needed," did things like climb into the backseat while the car was traveling down the highway. ${ }^{128}$

In at least one case, failure to properly monitor a Level 2 vehicle led to a fatality. On May 7, 2016, a Tesla Model S collided with a tractor trailer that had made a left turn in front of it at an intersection of a highway in Florida, killing the Tesla's driver. ${ }^{129}$ According to NHTSA's post-accident report,

Data obtained from the Model S indicated that: 1) the Tesla was being operated in Autopilot mode at the time of the collision; 2) the Automatic Emergency Braking (AEB) system did not provide any warning or automated braking for the collision event; and 3) the driver took no braking, steering or other actions to avoid the collision. ${ }^{130}$

NHTSA's post-accident examination "did not identify any defects in the design or performance of the AEB or Autopilot systems of the subject vehicles nor any incidents in which these systems did not perform as designed." 131 Indeed, NHTSA noted, the automatic emergency braking system was "not designed to reliably perform in all crash modes, including crossing path collisions," and the Autopilot system required "the continual and full attention of the driver to monitor the traffic environment and be prepared to take action to avoid crashes." 132 The driver, however, failed to pay such attention: crash reconstruction data "indicate[d] that the tractor trailer should have been visible to the Tesla driver for at least seven seconds prior to impact," long enough for him to have applied the brakes and avoided the crash altogether. ${ }^{133}$ Instead, there were reports in the immediate aftermath of the accident that the driver had likely been watching a Harry Potter movie on a DVD player that was found at the scene of the accident. ${ }^{134}$ Thus, NHTSA concluded, the crash appears to have been the result of "a period of extended distraction" 135 on the part of the driver rather than a "safety-related defect" inherent in the vehicle itself. ${ }^{136}$

Lest we too quickly accuse drivers of Level 2 vehicles of acting recklessly or irresponsibly, it is important to note that trying to maintain constant focus on the road while sitting behind the wheel of a car that is essentially driving itself is an objectively difficult task. Drivers have nothing to do other than watch the road, and so it

128. Ingrassia et al., supra note 39.

129. NAT'L HighwAY TRAFFiC SAFETy AdMIN., supra note 2.

130. Id. at 1 .

131. Id.

132. Id.

133. Id.

134. Mahita Gajanan, Tesla Driver May Have Been Watching Harry Potter Before Fatal Crash, VANITY FAIR (July 2, 2016, 12:27 PM), http://www.vanityfair.com/news/2016/07/tesladriver-may-have-been-watching-harry-potter-before-fatal-crash [https://perma.cc/RNN2-SHGZ].

135. NAT'L Highway Traffic SAFETy Admin., supra note 2, at 9.

136. Id. at 11-12. NHTSA apparently does not view the likelihood of a driver becoming distracted in an Autopilot-driven Tesla as a safety-related issue inherent to the vehicle itself, a problem I explore at greater length below. 
should come as no surprise that they may be inclined to daydream, become distracted, or even drift off to sleep. ${ }^{137}$ NHTSA has deemed this an "underload" problem:

Automation removes some demand from the driver and places it upon the automated system. However, by removing some level of task demand from the driver, there may be an associated risk of drivers achieving a state of underload. This is a situation in which the driver is understimulated, which may lead to fatigue, boredom, reduced levels of operator alertness, and sensation-seeking behaviors. This is potentially of more concern in Level 2 vehicles where there is an expectation that the driver will monitor the performance of the automation. ${ }^{38}$

Unfortunately, even brief lapses of attention can be dangerous in a Level 2 vehicle, particularly one that is driving on a highway. One NHSTA report quoted a study by General Motors showing that a majority of driver distractions in Level 2 vehicles "occur for 3 seconds or less," but noted that NHTSA's "analysis of field incidents found that most [automobile crashes] developed in less than 3-4 seconds." 139

Level 2 cars, therefore, are something of a paradox. On the one hand, "[s]emiautonomous features have proven to improve vehicle safety so long as drivers continue to pay attention when vehicles or other objects suddenly enter their path." 140 On the other, the weight of available evidence suggests that drivers have a very difficult time doing exactly that: paying attention. ${ }^{141}$ Accordingly, as Toyota noted in its public comments to the Policy, "there is much ongoing research to be done to understand human behavior and interaction with automated driving systems, but also to mitigate complacency and misuse or abuse." ${ }^{142}$

\section{B. Driver Misconception Issues}

Second, a new body of evidence suggests that both the salespeople and drivers of Level 2 vehicles do not have a strong or thorough understanding of how the semiautonomous systems in their vehicles work or what their limitations are. This appears to be the result of several interrelated issues.

\section{Written Manuals and Onscreen Warnings}

To start, the primary source of information about the autonomous features of Level 2 cars appear to be owner's manuals and warnings that appear on the digital displays within the cars themselves. However, there is no guarantee that drivers will

137. See Andrew R. Swanson, "Somebody Grab the Wheel!': State Autonomous Vehicle Legislation and the Road to a National Regime, 97 MARQ. L. REV. 1085, 1095 n.58 (2014).

138. NAT'L Highway TrafFic SAFETy Admin., supra note 25, at 25.

139. Nat'L Highway Traffic Safety Admin., supra note 2, at 9.

140. Karsten \& West, supra note 116.

141. See supra notes 124-126.

142. Toyota Motor North America, Comment Letter on Federal Automated Vehicle Policy 8 (Nov. 22, 2016), https://www.regulations.gov/document?D=NHTSA-2016-0090-1043 [https://perma.cc/WP7S-QJNC]. 
either (a) read these sources of information carefully, and/or (b) understand the information contained within them even if they do. ${ }^{143}$ A quick scan of some of these car manuals suggest that even careful readers may have to parse the language therein carefully to understand how the autonomous features on their vehicles work. The 2016 BMW 7-series owner's manual, for example, provides this warning about its automatic cruise control system: "If a vehicle driving ahead of you suddenly swerves into your lane, the system may not be able to automatically restore the selected distance. This also applies to major speed differences to vehicles driving ahead of you, e.g., when rapidly approaching a truck." 144

There is no explanation as to what a "selected instance" is or what "restoring" it means. The second sentence is arguably even more confusing. Is the manual saying that the cruise control system will have a difficult time maintaining the selected speed if the vehicle is rapidly approaching another vehicle from behind, or that it may not be able to maintain proper distance from that vehicle?

The 2016 Volvo XC90 Owner's Manual is similarly abstruse: "If ACC changes targets from a moving vehicle to a stationary one at speeds above $20 \mathrm{mph}(30 \mathrm{~km} / \mathrm{h})$, the system will not react to the stationary vehicle and will accelerate to the previous set speed. The driver must actively apply the brakes to slow/stop the vehicle."145

The content of both of these warning is of critical importance. They point out a very significant limitation of automatic cruise control systems: while these systems can keep a vehicle at a safe distance behind moving cars that are in front of them, they cannot keep at a safe distance behind stationary cars that are in front of them and thus will not automatically brake if the vehicle is approaching, say, a car that is stopped at a stoplight. If a driver relies on automatic cruise control to stop their vehicle in such a situation, they will almost certainly collide with the stationary car in front them. However, the language used in Volvo's manual does not adequately convey this information because it is abstract, technical, and difficult to understand. The leading clause- - "[i]f ACC changes targets from a moving vehicle to a stationary one at speeds above $20 \mathrm{mph}$ "- manages to be remarkably technical and to bury the lede. ${ }^{146}$ The relevant safety issue is not the changing of the "target," it is that the vehicle can no longer be trusted to maintain a safe distance from the car in front of it if the driver does apply the brakes him or herself. It is, at best, highly unclear whether a Volvo driver skimming their owner's manual will understand the nature of this safety issue.

Additional questions need to be asked about whether owner's manuals and onscreen warnings are written for average or low reading comprehension ability, whether they can be easily understood by drivers for whom English is a second language, and/or whether they are likely to be read by drivers at all. Thus far, no attempts appear to have been made to answer any of these questions despite their implications for the safety of Level 2 vehicles.

143. See Karsten \& West, supra note 114.

144. Bayerische Motoren Werke, The BMW 7-Series: Owner's Manual 174 (2015).

145. Volvo Car Corp., XC 90: OWner's Manual 268 (2015) (emphasis in original).

146. Id. 


\section{Poorly Informed Salespeople}

Next, a recent study by researchers at the Massachusetts Institute of Technology (MIT) showed that most salespeople of Level 2 vehicles "were themselves unfamiliar with how new safety features worked." ${ }^{147}$ Wired reports:

Last spring, undercover researchers from MIT's Agelab interviewed salespeople at 18 Boston-area dealerships. They were out to see how much these retailers knew about the increasingly common automated driver assistance programs they were selling, like crash avoidance, lane keeping, adaptive cruise control, and blind spot monitoring.

The results: Not nearly enough. Just six of the 17 salespeople gave "thorough" explanations of the technologies in the vehicles they were selling; four gave "poor" ones. According to the researchers, at least two provided almost dangerously incorrect info. One explained Ford's pedestrian detection technology is active at all speeds - even though it doesn't turn on until you're going at least $30 \mathrm{mph}$.... . Another said drivers did not have to brake while using Chevrolet's parking assist tech. They do. ${ }^{148}$

Given that car dealerships play a "crucial role" in delivering information about how automated technologies work, this study should be of significant concern. ${ }^{149}$ Another researcher of Level 2 vehicles encountered a similar problem in Washington, D.C.: car salespeople who "would mis-explain, wouldn't know what I was looking for, wouldn't know how to navigate the driver through the menus to see what the settings were." 150

Furthermore, consumers who do not fully understand the automated systems in their Level 2 cars may opt to turn off important warning systems that deliver additional critical safety information about the vehicle, leading to even greater ignorance about the machines that they are piloting. Yet another recent study showed that of " 265 Hondas brought in for servicing at dealerships in and around Washington, DC, less than a third still had their lane departure warnings turned on," leading journalists to conclude that if drivers "don't know why their car is making that gotdang dinging noise - they won't use 'em."151

\section{Naming Issues}

Lastly, the names of some of these automated systems may be misleading. For example, some jurisdiction and consumer groups have raised significant concerns about Tesla's use of the word "Autopilot" to describe its Level 2 system. ${ }^{152}$ Others

147. Karsten \& West, supra note 114.

148. Aarian Marshall, Car Dealers Are Dangerously Uneducated About New Safety Features, WiRED (Jan. 10, 2017, 7:00 AM), https:/www.wired.com/2017/01/car-dealersdangerously-uneducated-new-safety-features [https://perma.cc/T9L3-7R4M].

149. Id.

150. Id.

151. Id. (emphasis in the original).

152. NAT'L Highway TrafFic SAFETy Admin., supra note 2, at 4 n.9. 
have raised similar concerns about Mercedes-Benz's use of the name "Drive Pilot," complaining that names like these "give the false and dangerous impression that these cars are more capable than they really are." ${ }^{153}$ They also argue that these kinds of names can create driver confusion by suggesting that the vehicle can drive itself even though the manual or in-vehicle warnings indicate that the driver may need to retake control at a moment's notice. ${ }^{154}$

Indeed, to the extent that the word "autopilot" leads drivers of Level 2 vehicles to associate the autonomous systems in their cars with the autopilot systems on airplanes and large ships, they would be making an improper and problematic comparison. One scholar aptly describes the "critical differences" between these types of systems:

[A]utopilots on ships and airplanes are limited to devices designed to maintain a singular course or direction by passively reacting to variations in limited, discrete outside conditions (like wind or current). Autonomous vehicles, on the other hand, will be required to interact with complex, evolving environments (e.g., traffic, unexpected events), and to make affirmative choices so as to safely arrive at the destination (e.g., what lane to be in, what exit to take). Thus, because autonomous vehicle technology may be most valuable given some reduced level of oversight, and because the technology involves substantially different expectations regarding expectations and capabilities, an analogy to ship and airplane autopilots is unenlightening. ${ }^{155}$

However, with highly technical manuals and poorly informed salespeople as their primary sources of information about their vehicles, Level 2 drivers may rely fairly heavily (either consciously or unconsciously) on such comparisons in attempting to understand their vehicles.

\section{Consequences}

When drivers do not understand how the semi-autonomous systems in their cars work, accidents can happen and injuries or fatalities can result. Notably, these accidents can happen both when a driver engages and disengages the autonomous systems in his or her car. In the example provided above, a driver that engages automatic cruise control may have an accident if he or she does not understand that the system will not automatically brake to avoid a crash with a stationary vehicle. Another example highlights a similar issue when the driver chooses to disengage an autonomous system:

153. What You Need To Know About Semi-Autonomous Technology, Consumer ReP. (Oct. 24, 2016), http://www.consumerreports.org/self-driving-cars/what-you-need-to-know-aboutsemi-autonomous-technology [https://perma.cc/29S4-7P3H].

154. Tesla's Autopilot: Too Much Autonomy Too Soon, Consumer ReP. (July 14, 2016), http://www.consumerreports.org/tesla/tesla-autopilot-too-much-autonomy-too-soon [https:// perma.cc/4GSC-7BY3].

155. Dylan LeValley, Note, Autonomous Vehicle Liability-Application of Common Carrier Liability, 36 Seattle U. L. ReV. 5, 10 (2013). 
Consider the act of disengaging [automatic cruise control] and lane centering. The operator must first provide a disengagement input (e.g., button press on dashboard) informing the vehicle subsystem that the operator is willing and prepared to take over responsibility for maintaining speed and/or heading [(i.e., steering)]. The vehicle subsystem may then acknowledge the input with a feedback mechanism(s) that provides confirmation to the operator. A time period then passes before the automated component disengages, and the operator becomes responsible for speed and heading.

There may be potential for operational issues if the operator is not aware of certain specific tasks for which he/she is accepting responsibility. Should the operator believe he/she has only accepted responsibility for speed maintenance, for example, a potential conflict arises regarding authority for vehicle heading. Essentially, the operator may incorrectly assume the vehicle is still maintaining heading when, in fact, neither subsystem is actively steering the vehicle. ${ }^{156}$

Thus, without an adequate understanding of their Level 2 vehicles, drivers cannot reliably operate their vehicles safely and may, in fact, generate significant amounts of risk for both themselves and other drivers on the road.

\section{RECOMMENDED FEDERAL REgULATIONS}

The issues discussed at length above create unnecessary risks on U.S. roads, and thus lawmakers should respond by regulating Level 2, semi-autonomous cars as their own unique type of vehicle, rather than by improperly categorizing them with fully autonomous vehicles or more traditional human-driven cars. ${ }^{157}$ Due to the bifurcated way that automobiles are regulated in this country, however, this response must happen at both the federal and state levels. The federal government, through the DOT and NHTSA, regulates vehicle design and equipment and sets safety standards for all new automobiles sold in the United States, whereas states regulate driver behavior and motor vehicle operation by setting traffic laws and controlling the issuance of driver's licenses. ${ }^{158}$ While there is strong argument to be made that this jurisdictional division may need to change at some point in the future as motor vehicle operation falls increasingly under the domain of a motor vehicle's equipment (NHTSA's responsibility) rather than a human driver (a state's responsibility), for purposes of this paper, the current jurisdictional divisions will be respected. ${ }^{159}$

To start, three changes should be made with respect to federal regulation of Level 2 cars: (1) the introduction of a premarket approval process, (2) the mandating of attention warning systems within these vehicles, and (3) the passage of truth-in-naming regulations. While industry often resents greater federal regulation of their goods, traditional automakers, tech companies, and legal scholars have lobbied for greater federal involvement in the regulations of autonomous vehicles. ${ }^{160}$ The president of

156. Nat'l Highway Traffic Safety Admin., supra note 25, at 21.

157. Ford Motor Co., supra note 44, at 5.

158. NAT'L HighwAY TRAFFiC SAFETy AdMin., supra note 9, at 38; Kessler, supra note 98.

159. See Davies, supra note 66.

160. Id.; see also WEAVER, supra note 68, at 50-51; Brad Plumer, Here's What It Would 
Volvo, for instance, has lobbied for "one set of rules to regulate the operation of and liability for autonomous vehicles, not a piecemeal approach by 50 states." ${ }^{161}$ NHTSA has signaled its interest in regulating semi-autonomous cars, as well, reporting that "[d]river misuse in the context of semi-autonomous vehicles is an emerging issue and the agency intends to continue its evaluation and monitoring of this topic, including best practices for handling driver misuse as well as driver education." ${ }^{162}$ Thus, there appears to a general interest in the federal government passing the types of regulations proposed below, although the particular regulations being proposed might be met with industry objection.

\section{A. Premarket Approval}

First, Congress should grant NHTSA the ability to create and administer a premarket approval system for Level 2, semi-autonomous vehicles. Currently, as discussed above, no such approval is required. ${ }^{163}$ Instead, automobile manufacturers are free to place any form of automation into their vehicles as long as those systems comply with the Federal Motor Vehicle Safety Standards (which do not address the safety of autonomous or semi-autonomous driving systems at all and are thus largely irrelevant to the safety of semi-autonomous vehicles). ${ }^{164}$ NHTSA has also requested that entities "voluntarily provide the agency with a Safety Assessment Letter outlining how the [Policy] has been followed." 165 As noted, however, there appear to be no consequences for choosing not to submit such a letter. ${ }^{166}$

While many industry players have insisted that this current arrangement is reasonable, and that " $[t]$ o the extent that NHTSA has specific concerns about the potential safety of level 1 and/or 2 driving automation features, it should use its existing defect authority to address such concerns," ${ }^{167}$ NHTSA's existing defect authority is insufficiently protective of human safety in the context of semi-autonomous vehicles for two reasons: (a) NHTSA's existing defect authority is reactive rather than proactive and (b) NHTSA's existing defect authority does nothing to stop manufacturers

Take for Self-Driving Cars To Catch On, WAsh. Post (Oct. 23, 2013), http://www.washingtonpost.com/blogs/wonkblog/wp/2013/10/23/heres-what-it-would-takefor-self-driving-cars-to-catch-on [https://perma.cc/VW52-Z6WP]; John Villasenor, Products Liability and Driverless Cars: Issues and Guiding Principles for Legislation, Brookings (Apr. 24, 2014), https://www.brookings.edu/research/products-liability-and-driverless-carsissues-and-guiding-principles-for-legislation [https://perma.cc/YTZ5-4B9Q].

161. Putre, supra note 66.

162. NAt'L Highway Traffic SAfEty Admin., supra note 2, at 10 n.20.

163. See Nat'L Highway Traffic Safety Admin., supra note 9, at 48.

164. Id.

165. Consumer Reports \& Consumers Union, supra note 94, at 3.

166. See supra note 101 and accompanying text.

167. Mercedes-Benz, supra note 109, at 3; see also Volvo Car Corp., Comment Letter on Federal Automated Vehicle Policy 3 (Nov. 22, 2016), https://www.regulations.gov/ document?D=NHTSA-2016-0090-1018 [https://perma.cc/4KAQ-3QQ8] ("Volvo Cars believes NHTSA should use its existing authority for SAE level 1 to 2 vehicles and the federal guidelines should apply only to SAE levels 3 to 5 ."). 
and developers from "beta-testing" new forms of vehicle autonomy on unwitting consumers. ${ }^{168}$

With regard to the first issue, NHTSA's existing defect authority is an insufficient source of regulation for Level 2 vehicles because it is reactive rather than proactive. One scholar explains:

The Safety Act generally gives NHTSA the ability to order recalls of autonomous driving technologies because of defects present in the components of those technologies or because of defects attributable to the improper installation of the technology by an alterer. [However, i]n order to establish a defect, NHTSA must show a significant number of performance failures. ${ }^{169}$

This means that NHTSA must wait until a Level 2 system reveals itself to be dangerous, likely through a series of automobile accidents, before it can step in and take action. ${ }^{170}$ This is both inefficient and risky for drivers. While NHTSA should absolutely retain its defect authority powers - as sometimes defects only reveal themselves over time and millions of miles driven - those powers needs to be supplemented with the ability to investigate and (where necessary) regulate Level 2 technologies before they come to market in order to prevent needless injuries or fatalities.

Additionally, without a premarket approval system in place, the risk of injuries or death may be inexcusably high: manufacturers and developers can exploit the lack of premarket regulation and "beta-test" new semi-autonomous systems on consumers without any assurances in advance that those systems are safe. ${ }^{171}$ Indeed, arguably, manufacturers are more likely to beta-test semi-autonomous technologies than fully autonomous ones on actual consumers: since drivers are supposed to be monitoring the semi-autonomous systems in their Level 2 vehicles at all times, manufacturers can easily blame driver inattention or distraction if something goes wrong, thus minimizing their liability. This issue is of such concern that even Consumer Reports has spoken out about it:

"Consumers should never be guinea pigs for vehicle safety 'beta' programs," [Laura MacCleery, vice president of consumer policy and mobilization for Consumer Reports] says. "At the same time, regulators urgently need to step up their oversight of cars with these active safety features. NHTSA should insist on expert, independent third-party testing and certification for these features, and issue mandatory safety standards to ensure that they operate safely." 172

Only a premarket approval process can provide assurance that semi-autonomous systems have an acceptable risk profile before their entry onto U.S. roads.

168. See infra notes 170-173.

169. Stephen P. Wood, Jesse Chang, Thomas Healy \& John Wood, The Potential Regulatory Challenges of Increasingly Autonomous Motor Vehicles, 52 SANTA ClARA L. REV. 1423, 1488-89 (2012).

170. See id.

171. Tesla's Autopilot: Too Much Autonomy Too Soon, supra note 154.

172. Id. 


\section{B. Mandatory Attention Warning Systems}

Second, NHTSA should mandate the installation of attention warning systems on all semi-autonomous vehicles because, as discussed above, unlike Level 3, 4, and 5 vehicles which require little or no human supervision, the safety of Level 2 vehicles "cannot be ensured ... without an engaged and vigilant driver in the loop." 173 These systems should be able to both monitor the level of engagement of the driver and "take the vehicle to a safe fall back condition if the monitor determines the driver is not sufficiently engaged." ${ }^{174}$ Currently, NHTSA strongly suggests that manufacturers install such warning systems into their Level 2 vehicles, but doing so is not required under any NHTSA policies or regulations. ${ }^{175}$

As the safety studies discussed above reveal, attention warning systems are a critical component of the safety of semi-autonomous cars because verbal and written warnings are not enough. ${ }^{176}$ In each of the studies or test protocols cited, drivers were verbally instructed to monitor the road continuously and yet, in each of those studies, a significant percentage of the drivers had an extremely difficult time doing so. ${ }^{177}$ The effectiveness of written warnings is even more questionable. ${ }^{178}$ While, ideally, all drivers would carefully pore over the owner's manuals of their vehicles, "the reality is that drivers do not always do so," and so manufacturers should design their vehicles accordingly. ${ }^{179}$

Furthermore, NHTSA should mandate that these attention warning systems be both intuitive and standardized. ${ }^{180}$ The warning chimes and/or lights that provide the alerts in one type of semi-autonomous car should be the same as the warning chimes and/or lights that provide the alerts in other semi-autonomous cars. Thus, for instance, if an owner of one type of semi-autonomous car goes on vacation and rents another type, that driver should not have to learn a new series of alerts that would signal that he or she needs to pay closer attention to the road. This form of intuitive

173. NAt'L Highway Traffic SAFETy Admin., supra note 9, at 33. These warning systems should only be required in instances in which a driver has engaged semi-autonomous features that allow him or her to disengage from more than one driving task at a time. They should not be mandated for use with other driver assistance technologies such as automatic braking or lane keeping assistance that only prove "momentary intervention." DENSO Corp., Comment Letter on Federal Automated Vehicle Policy (Nov. 22, 2016), https://www.regulations.gov/ document?D=NHTSA-2016-0090-1091 [https://perma.cc/SEX3-3G8H].

174. NAt'L Highway Traffic Safety Admin., supra note 9, at 32.

175. Self-Driving Car Guidelines: Not Enough Protection for Consumers, Consumer ReP. (Sept. 20, 2016), http://www.consumerreports.org/self-driving-cars/self-driving-car-guidelinesnot-enough-protection-for-consumers [https://perma.cc/8TLN-97TH].

176. Peter Kurdock, Statement from NHTSA Public Meeting on Federal Automated Vehicles Policy, Advocs. for Highway \& Auto SAfety, (Nov. 10, 2016), http://saferoads.org/2016/11/10/2182 [https://perma.cc/HF9T-UFTT].

177. Goodall, supra note 122; Ingrassia et al., supra note 39; Llaneras et al., supra note 117 , at 94 .

178. See supra notes 143-146 and accompanying text.

179. NAT'L HighWAY TRAFFIC SAFETY ADMIN., supra note 2, at 11 n.23.

180. Id. at 5; BMW Grp., Comment Letter on Federal Automated Vehicle Policy (Nov. 22, 2016), https://www.regulations.gov/document?D=NHTSA-2016-0090-1111 [https://perma.cc/ JFP5-LLWC]; Delphi, supra note 91; Consumer Reports \& Consumers Union, supra note 94. 
design and standardization "would help ensure drivers quickly understand the situation, as well as provide continuity for drivers moving from vehicle to vehicle." 181 BMW is already attempting to take this approach by making their semi-autonomous system as intuitive as possible:

During design and development of automated functions, BMW takes into consideration reactions of the driver so that extensive additional training of the driver is not required. BMW aims to make the driving experience as intuitive as possible. Vehicle functions should be generally controllable while also taking into account potential misuse.

In general, as any one vehicle can have multiple drivers, BMW believes that OEMs should not rely heavily on consumer training, but should consider the drivers' reactions in development. ${ }^{182}$

These systems should be intuitive and standardized not only with regard to what forms of alarms or consequences are triggered when a driver does not pay adequate attention to the road, but also with regard to how long a driver can be inattentive before they are triggered. Consumer Reports, for example, found that it took more than three minutes after a driver's hands were removed from the steering wheel before a Tesla Model S sounded any warnings. ${ }^{183}$ Other systems may sound alarms much sooner than that.

Additionally, there are already substantive differences in how these systems work. Tesla, for example, monitors driver attention through the steering wheel in their models:

If the system does not detect the driver's hands on the steering wheel (assessed using microtorque measurements) or other signs of driver engagement for periods of time that vary depending on road class, vehicle speed, road curvature, and traffic conditions, an escalating series of warnings is presented. The warnings start with a visual alert indicating that hands on the steering wheel are required. If the driver does not respond to the visual warning, an audible chime is sounded after $15 \mathrm{sec}-$ onds. A more pronounced chime is initiated if the driver does not respond after another 10 seconds. If the driver fails to respond to the third alert stage within five seconds, the system gradually slows the vehicle while maintaining position in the lane. Once the driver's hands are detected on the steering wheel, the warnings are suspended and Autopilot operation resumes. ${ }^{184}$

As part of a September 2016 over-the-air software update, Tesla also added an "Autopilot strikeout" feature that removes the ability of the driver to use the semi-

181. Delphi, supra note 91.

182. BMW Grp., supra note 180 , at 7.

183. Tesla's Autopilot: Too Much Autonomy Too Soon, supra note 154.

184. NAT'L Highway Traffic SAFETy Admin., supra note 2, at 7. 
autonomous Autopilot system entirely for the remainder of a drive if the driver repeatedly fails to respond to alerts. ${ }^{185}$ GM's attention warning system works differently, using sensors behind its steering wheels "that continuously scan[] the driver's eyes and face." ${ }^{186}$ If the system detects that a driver is not watching the road, the driver's seat will vibrate. If the vibrations aren't sufficient to induce the driver to pay attention, alarm chimes and warnings lights will engage. ${ }^{187}$ If the second round of warnings doesn't work, the system will slow the car down or bring it to a stop entirely. ${ }^{188}$ These differences in warnings systems should be addressed by NHTSA in favor of a more standardized approach.

Even though current manufactures like Tesla and GM are placing attention warnings systems into semi-autonomous vehicles, we cannot be confident that manufacturers will continue to do so in the future, particularly as new manufacturers enter into the development and sale of semi-autonomous cars for the first time. In fact, there may be market incentives not to include these warnings systems which will almost certainly annoy drivers who over-trust the technology and thus want to be able to be distracted while their vehicles are driving in semi-autonomous mode. For instance, there might be a strong market for semi-autonomous vehicles that promise to let drivers go for longer without paying attention to the road or that promise to "trust" drivers more and sound alarms less. Without a NHTSA regulation requiring such systems, consumers can only hope that the "[s]ubstantive human factors challenges" of semi-autonomous vehicles are being met by manufacturers. ${ }^{189}$

Determining which attention warnings systems are most effective at generating the desired driver response - a return of their attention to the road-will likely require additional research. This research should be designed to address a number of different factors:

There may also be some benefit to future system design from research into methods or techniques to handle ignored cues or to determine why the cues were ignored (e.g., potential misuse). When a cue is present but no operator subsystem action is taken, it may be of value to investigate the best course of action for the vehicle subsystem (e.g., increase in cue volume or secondary alert [e.g., haptic] supplemental to original alert [e.g., auditory]). In addition, research could provide input into the timing, sequence, and presentation of such cues for optimal system function. ${ }^{190}$

Only through answering these questions can we solve the fundamental riddle posed by Level 2 cars: "How to get owners to trust the technology so they'll use itbut not trust it so much that they'll be lulled into a false sense of security and therefore slower to react when the car needs them."191

185. Id.

186. Keith Naughton, Can Detroit Beat Google to the Self-Driving Car?, BLOOMBERG BUSINESSWEEK (Oct. 29, 2015), http://www.bloomberg.com/features/2015-gm-super-cruisedriverless-car [https://perma.cc/AS59-7MVK].

187. Id.

188. Id.

189. Llaneras et al., supra note 117 , at 93.

190. NAT'L Highway TrafFic SAFETy AdMin., supra note 25, at 22.

191. Pritchard, supra note 42. 


\section{Truth in Naming}

Third, NHTSA should forbid vehicle manufacturers from naming their semi-autonomous systems in such a way that they give consumers a false impression of how robust the technology is or how independently it can operate without driver attention. ${ }^{192}$ Names such as "Autopilot" (Tesla's system) and "Drive Pilot" (Mercedes's system) "can give the false and dangerous impression that these cars are more capable than they really are," and thus lure drivers into making choices that undermine the safety of these vehicles. ${ }^{193}$ Those kinds of names can also create confusion for conscientious drivers by generating conflicting messages: (a) that the vehicle can drive itself while operating in semi-autonomous mode (as indicated by the name of the semi-autonomous system) but (b) that drivers need to monitor the vehicle while operating in semi-autonomous mode (as indicated by the driver's manual or onscreen warnings). ${ }^{194}$

One jurisdiction has already acted on these concerns. In October 2016, the California Department of Motor Vehicles released draft regulations that would ban the word "Autopilot" from Tesla's advertising. ${ }^{195}$ The Washington Post reported:

"The terms 'self-driving,' 'automated,' 'auto-pilot,' and other statements that lead a reasonable person to believe a vehicle is autonomous constitute advertising regulated by the truth-in-advertising provisions in the Vehicle Code," the state said. A true autonomous vehicle that could use such terms, California says, is one that is "equipped with technology that has the capability of operating or driving the vehicle without the active physical control or monitoring of a natural person." 196

In other words, California believes that words like "autopilot" are only used appropriately to describe vehicles with Level 3 automated systems or higher, not Level 2 vehicles. ${ }^{197}$ NHTSA should follow California's lead.

\section{RECOMMENDED STATE LAWS}

Given the bifurcated nature of oversight of motor vehicles, statutes and regulations also need to be passed at the state level in order to ensure the safety of

192. Consumer Reports \& Consumers Union, supra note 94.

193. What You Need To Know About Semi-Autonomous Technology, supra note 153.

194. Tesla's Autopilot: Too Much Autonomy Too Soon, supra note 154.

195. Cal. Dep't of Motor Vehicles, ARt. 3.7-Autonomous Vehicles § 227.90, https:// www.dmv.ca.gov/portal/wcm/connect/211897ae-c58a-4f28-a2b7-03cbe213e51d/avexpressterms_ 93016.pdf?MOD=AJPERES [https://perma.cc/7ZLC-CLSQ].

196. Michael Laris \& Ashley Halsey III, California's Proposed Rules for Driverless Vehicles Take Aim at Tesla, WASH. Post (Oct. 1, 2016), https://www.washingtonpost.com/ local/trafficandcommuting/californias-proposed-rules-for-driverless-vehicles-take-aim-at-tesla/ 2016/10/01/b091d930-87df-11e6-92c2-14b64f3d453f_story.html [https://perma.cc/795N-DDMG].

197. James Ayre, California DMV Issues Draft Regulation Demanding that Tesla Stop Using Terms “Autopilot," "Self-Driving," \& "Automated" in Advertising, CleAn TeChNiCA (Oct. 10, 2016), https://cleantechnica.com/2016/10/10/california-dmv-issues-draft-regulation-demandingtesla-stop-using-terms-autopilot-self-driving-automated-advertising [https://perma.cc/5A6A-P583]. 
semi-autonomous vehicles. ${ }^{198}$ While the federal government is best situated to regulate the design and equipment of these vehicles, states are currently the only entities with jurisdiction over driver behavior, traffic laws, and licensing. ${ }^{199}$ To that end, several laws pertaining to the operation of semi-autonomous cars appear to be warranted.

\section{A. Tampering with or Disabling Driver Monitoring Systems}

First, states should make it illegal for drivers to tamper with or disable the attention warnings systems in their vehicles. ${ }^{200}$ Drivers might be inclined to do so either (a) so they can pay less attention to the road (intentionally) without consequences from the attention monitoring system or (b) because they find those warning systems frustrating or annoying. ${ }^{201}$ Indeed, "[d]ata is now showing that some advanced driver assist systems for safety are being turned off or ignored by drivers because their notifications are ... distracting for the driver." ${ }^{\text {202 }}$ Drivers who want to disable these systems could do so by removing their physical components from the vehicle or by "sending signals to jam the technology." 203

To the extent that drivers do either of these things intentionally and "in a manner that the operator knows to be against the design and intent of the automated component," those drivers should be subject to criminal charges. ${ }^{204}$ At least one scholar has called for this sort of misuse to be deemed reckless driving because it impacts whether the vehicle can be operated safely and thus creates a risk to other vehicles and drivers on the road. ${ }^{205}$ Punishing the driver, therefore "would deter the person from future alterations to her autonomous vehicle, deter others contemplating alterations to their vehicles, and punish the individual for causing harm to others or property." 206

\section{B. Update and Maintenance Requirements}

Second, drivers of semi-autonomous vehicles should be required to install all over-the-air software and firmware updates within a reasonable amount of time of their availability. ${ }^{207}$ Such updates can provide, among other things, critical safety

198. NAt'L Highway Traffic Safety Admin., supra note 9, at 39.

199. Id. at 38; Kessler, supra note 98.

200. See Gurney, supra note 64, at 432.

201. Id.; Auto Care Assoc., Comment Letter on Federal Automated Vehicle Policy (Nov. 22, 2016), https://www.regulations.gov/document?D=NHTSA-2016-0090-1090 [https://perma.cc/ D8C9-HEPJ].

202. Auto Care Assoc., supra note 201, at 5. Additional studies are needed to determine whether these notifications are distracting because they are confusing or because they interfere with the driver's desire to drive (or monitor) the vehicle in a particular way. NAT'L HIGHWAY TrafFic SAFETy Admin., supra note 25, at 21.

203. Gurney, supra note 64, at 432.

204. NAT'L HighwAy TRAFFiC SAFETy AdMin., supra note 25, at 21.

205. Gurney, supra note 64 , at 425.

206. Id.

207. NAT'L Highway Traffic SAFEty AdMin., supra note 9, at 37 ("NHTSA also hopes 
patches, improvements to the autonomous features of the car, fixes for software or firmware problems that have come to light, and even new safety features. ${ }^{208}$ These updates come to semi-autonomous vehicles typically through a Wi-Fi signal or the car's own network connections, rather than from a trip to a service center or dealership. Additionally, these updates can arrive fairly frequently. For example:

Since it released Autopilot in October 2015, Tesla has made continuous updates to the system's firmware that are made available to consumers as [over-the-air] updates. These updates have included changes to improve TACC, AEB and Autosteer performance, as well as adding new driver assistance safety features, such as In-Path Stationary Object (IPSO) braking and Pedal Misapplication Mitigation (PMM). In September 2016, Tesla released its 8.0 firmware update which included revisions in the driver monitoring strategy, as well as several enhancements to AEB, DBS, and TACC performance. ${ }^{209}$

Choosing to install these updates is as simple as pushing a button and thus requires virtually no effort on the part of owners or drivers of semi-autonomous vehicles. ${ }^{210}$ In Teslas, for example, when an update is available, drivers are "notified on the center display with an option to install immediately, or schedule the installation for a later time." ${ }^{211}$ Both of these choices can be made on the center display itself, which functions as a touchscreen computer. ${ }^{212}$

Installing these updates is an important part of the maintenance of semi-autonomous vehicles because it ensures that the semi-autonomous systems are as up-to-date and safe as possible and that each individual semi-autonomous vehicle can benefit from "fleet learning." ${ }^{13}$ A recent article from The New Yorker explains:

The software that runs autonomous vehicles is constantly learning from real-world driving data, getting better at recognizing things around it (the road, other cars, nearby trees) and deciding how to respond (steering, braking). All the information is transmitted to a centralized brain and used to make the fleet smarter. This sharing, or "fleet learning," is incredibly powerful. It's kind of like how, when your finger touches a hot stove, your foot, knee, and elbow also learn that it's not a good idea to touch a hot stove. ${ }^{214}$

to partner with the States to identify and mitigate other human behavior issues such as misuse and inadequate maintenance of HAVs." (emphasis added)).

208. See Nat'l Highway Traffic Safety Admin., supra note 2, at 11.

209. Id.

210. Support: Software Updates, TESLA, https://www.tesla.com/support/software-updates [https://perma.cc/4T6X-C2QQ].

211. Id.

212. Id.

213. Levi Tillemann \& Colin McCormick, Will Driverless-Car Makers Learn To Share?, NEW YORKER (Sept. 25, 2016), http://www.newyorker.com/business/currency/will-driverlesscar-makers-learn-to-share [https://perma.cc/PSF6-6FF9].

214. Id. 
The semi-autonomous vehicles of drivers that choose not to install over-the-air updates do not benefit from this learning and may retain otherwise fixable system defects or safety issues that would be corrected if the updates are installed.

A law or regulation requiring regular updates of semi-autonomous systems would be consistent with most states' existing motor vehicle codes. A large number of states have laws requiring the annual inspection of all vehicles registered within the state. ${ }^{215}$ Similarly, many states have laws requiring driver maintenance of vehicles when, for instance, a police officer finds a condition on a vehicle that they deem to be unsafe or to pose a risk to other people. ${ }^{216}$ Requiring drivers of semi-autonomous cars to install over-the-air updates within a reasonable amount of time would not only be less burdensome than these types of laws but also fulfill the same purpose: ensuring that all vehicles on state roads are safe and lacking any obvious defects or safety hazards.

\section{Mandatory Consumer Training}

Third, states should consider passing laws that require drivers of semi-autonomous cars to obtain preapproved training on the capabilities and limitations of semiautonomous vehicles. ${ }^{217}$ As discussed at length above, drivers who do not fully understand how the semi-autonomous systems in their vehicles work may wind up injuring themselves or others by, for instance, failing to brake when necessary out of a belief that the vehicle will do so instead or failing to monitor the vehicle appropriately because the driver has a false sense of what the vehicle is capable of handling. ${ }^{218}$ Indeed, the need for driver education is arguably more important in Level 2 vehicles than it is in Level 3, 4, or 5 vehicles because drivers of Level 2 cars are at greater risk of believing that their vehicles are much more capable of driving on their own than they actually are. ${ }^{219}$

While, currently, some information is provided to consumers via owner's manuals, on-screen notifications, and car dealerships (with varying degrees of accuracy), ${ }^{220}$ "there is a clear need, especially for vehicles that may require the intervention of a driver or which can have their operational capabilities updated significantly, for important features of the AV system operation to be delivered to consumers in

215. See, e.g., N.Y. Veh. \& Traf. LaW § 301(a) (McKinney Supp. 2017); 75 Pa. Stat. And Const. Stat. Ann. § 4702(a) (West Supp. 2017); Tex. Transp. Code Ann $§ 548.101$ (West Supp. 2017); VA. Code AnN. § 46.2-1158 (Supp. 2017).

216. See, e.g., Ark. Code Ann. § 27-32-101 (LexisNexis 2017); Fla. Stat. Ann. § 316.610 (West Supp. 2018); MonT. CodE ANN. § 61-9.501 (2017).

217. Kurdock, supra note 176.

218. NAT'L Highway Traffic SAfETy Admin., supra note 25, at 19 (“Automation across any domain has the potential to present difficulties when users' reliance upon the automation is not properly calibrated to the performance."); see also Pritchard, supra note 42 ("New cars that can steer and brake themselves risk lulling people in the driver's seat into a false sense of security - and even to sleep.").

219. Consumer Watchdog, supra note 93.

220. There is also an argument to be made here that states require employees at dealerships that sell Level 2 vehicles to undergo the same sort of training given that these employees often provide informal training to consumers about these vehicles. Marshall, supra note 148. 
other ways." ${ }^{221}$ This is particularly true given both that (a) not all drivers may read the owner's manual of a vehicle before driving it, and (b) written instructions or information appearing in manuals or on-screen warnings may be difficult to comprehend for various reasons. ${ }^{222}$

Better sources of consumer information might include video tutorials created by car manufacturers that could be viewed on mobile phones, tablets, computers, or even on the screens located within the semi-autonomous vehicles themselves. ${ }^{223}$ States could mandate that such videos be viewed by purchasers of new semi-autonomous cars at car dealerships before the dealership is permitted to hand over the keys to these vehicles. There could even be brief tests after the conclusion of those videos if research determines that such tests enhance driver comprehension. ${ }^{224}$ Similarly, car manufacturers could require drivers to "unlock" the semi-autonomous options (and/or updates) in their cars prior to use by entering a code that is provided only upon successful completion of a tutorial, video, or quiz on the car manufacturer's website.

While the exact content of such tutorials or consumer training would have to be targeted to each particular type of Level 2 vehicle, at a bare minimum, all such tutorials should provide consumers with information about (1) the limitations of Level 2 systems, and (2) the critical differences between Level 2 vehicles and vehicles with a higher level of automation. With regard to the first, drivers should be notified that semi-autonomous systems are not foolproof and that driver intervention is required in a number of common driving scenarios. For example, as discussed above, autonomous cruise control (ACC) systems are capable of both slowing down and speeding back up to the selected speed in response to the movements and speeds of automobiles nearby. However, ACC systems will not brake in response to cars that have come to a full stop in front of the vehicle. ${ }^{225}$ In those scenarios, drivers must brake themselves in order to avoid a collision. ${ }^{226}$ Similarly, most Level 2 vehicles cannot operate reliably in semi-autonomous mode during bad weather, when there are faded lane markings, or in limited visibility conditions. ${ }^{227}$ Drivers must understand these limitations to operate their vehicles safely.

With regard to the second form of information that should be provided to consumers-information about the differences between Level 2 vehicles and vehicles with higher levels of automation - it is also vitally important that consumers understand the differences between driving, say, a Level 2 vehicle and a Level 3 vehicle, or

221. Jacqueline S. Gillan, President, Advocs. For Highway \& Auto Safety, Statement on "Self-Driving Vehicle Legislation" to the Comm. On Energy \& Commerce 11 (June 27, 2017), http://saferoads.org/wp-content/uploads/2017/06/Advocates-Statement-to-House-Energy-andCommerce-Cmte-Hrng-6-27-17-FINAL-with-attachments.pdf [https://perma.cc/7HL5-9XDP].

222. See Nat'L Highway Traffic Safety Admin., supra note 2, at 11 n. 23.

223. See id.

224. Law Office of Stephen E. Selander, supra note 101.

225. NAT'L Highway Traffic SAfety Admin., supra note 2, at 8 (quoting Volvo Car CORP., supra note 145).

226. Id.

227. Sarah Karush, Driver Seat: Robot Cars Won't Retire Crash-Test Dummies Anytime Soon, Status ReP., Nov. 10, 2016, at 4, 6. 
(when eventually available) a Level 3 vehicle and a Level 4 vehicle. NHTSA explains:

Manufacturers and other entities should assume that the technical distinction between the levels of automation (e.g., between Level 2 and Level 3) may not be clear to all users or to the general public. And, systems' expectations of drivers and those drivers' actual understanding of the critical importance of their "supervisory" role may be materially different. ${ }^{228}$

Given the various rates at which tech companies and car manufacturers are due to release various levels of automation-Tesla claims it will have Level 4 vehicles on the market by 2018, Volvo will release small numbers of Level 3 cars by the end of 2017, and Cadillac will release its Level 2 Super Cruise system around roughly the same time - there will be at least a several year (if not decade-long) period during which automobiles of differing levels of automation will be on U.S. roads simultaneously. ${ }^{229}$ Drivers attempting to understand the capabilities of their own cars by looking to the capabilities of other cars - their neighbors', friends', co-workers', etc. - may not realize that they are comparing, in effect, a Level 2 apple to a Level 3 orange. Consumer training, therefore, must not only educate drivers about the capabilities and limitations of their own vehicles, but also stress that those capabilities and limitations are unique and that other automobiles may have different automated systems with greater or more limited amounts of automation.

NHTSA consumer advocates and scholars appear to favor a consumer education training requirement for drivers. ${ }^{230}$ In their public comments to the Policy, for instance, the Advocates for Highway and Auto Safety note:

This [training] is especially necessary for Level 3 (and lower) AVs in which the driver may need to take over control of the vehicle when the operational limits of the AV system have been reached. The suggestion in the NHTSA AV Policy that consumers who purchase AVs should receive training on the operational capabilities and limitations of the AV system they purchase, along with an on-the-road demonstration prior to taking possession of the AV would be beneficial. However, the agency should take the next step and offer specific solutions and develop prototype program materials to guide manufacturers in this effort. ${ }^{231}$

Encouraging states to put mandatory training programs in place for drivers of Level 2 vehicles would be consistent with their jurisdiction over drivers and motor

228. Nat'L Highway Traffic Safety Admin., supra note 9, at 32.

229. See Connor, supra note 5.

230. See, e.g., NAT'L Highway Traffic SAfETy Admin., supra note 2, at 10 n.20 ("Driver misuse in the context of semi-autonomous vehicles is an emerging issue and the agency intends to continue its evaluation and monitoring of this topic, including best practices for handling driver misuse as well as driver education."); Karsten \& West, supra note 116 ("If manufacturers introduce advanced safety features to stay competitive, then they must also train drivers on how to use [those] features in order to stay safe.").

231. Kurdock, supra note 176. 
vehicle operation and with their current practice. Indeed, states already impose different licensing and driving requirements for different types of vehicles. Texas, for instance, issues Class A, B, and C commercial driver's licenses, depending on, among other factors, the gross vehicle weight of the vehicles a driver intends to drive. ${ }^{232}$ Texas also requires drivers in possession of a commercial driver's license to obtain additional "endorsements" to do things such as transport hazardous materials, tow a double or triple trailer, or drive a tank. ${ }^{233}$ Likewise, California's motor vehicle code states that "[a] person may not operate a commercial motor vehicle described in this chapter unless that person has in his or her possession a valid commercial driver's license for the appropriate class, and an endorsement issued by the department to permit the operation of the vehicle." ${ }^{" 234}$ New York requires operators of commercial vehicles to obtain a special endorsement to operate vehicles carrying metal coils. ${ }^{235}$ It would be consistent with current state practice, therefore, for states to require license endorsements that were dependent upon completion of training and/or a test —or something similar - for drivers of semi-autonomous vehicles. ${ }^{236}$

However, states would have to address several issues to develop a reasonable and effective training protocol. First, it would be extremely difficult to standardize consumer training for Level 2 vehicles given that Level 2 vehicles vary in their capabilities and the ways in which their semi-autonomous systems are designed. Consumer training would almost certainly either (a) have to be targeted to each particular model of Level 2 car, which would seemingly require states to have to review and approve each manufacturer's unique training materials, or (more likely) (b) develop more general training materials aimed at educating drivers about each particular type of semi-autonomous system available (for instance, automatic cruise control, lane centering, etc.).

Second, if states require that all drivers of Level 2 vehicles complete training, Level 2 vehicles would seemingly be unable to be lent out to "standard drivers," and rental car companies would be unable to rent these types of vehicles to customers. This could, in turn, slow the adoption of driverless cars in general. Since the ultimate goal of both states and the federal government should be to improve highway safety by promoting the use of fully driverless cars, this should be of fairly significant concern. 237

Third, far from remaining static, most Level 2 vehicles are subject to over-the-air updates of their systems that both change and improve the semi-autonomous features of that vehicle. Teslas that were purchased after November 2016 with a "driverless package" are currently Level 2 vehicles but will likely evolve into Level 4 or 5 vehicles over time. ${ }^{238}$ Requiring a specialized license for a fully driverless car makes little

232. Tex. Transp. Code AnN. $§ 522.041$ (West Supp. 2017).

233. Id. $\$ 522.042$.

234. CAL. Veh. Code $§ 15275$ (a) (West Supp. 2018).

235. N.Y. Veh. \& Traf. LAW $§ 501$ (2)(ix) (McKinney Supp. 2017).

236. WEAVER, supra note 68, at 182.

237. NAT'L HighwAy TrafFic SAFETy Admin., supra note 10.

238. All Tesla Cars Being Produced Now Have Full Self-Driving Hardware, Tesla (Oct. 19, 2016), https://www.tesla.com/blog/all-tesla-cars-being-produced-now-have-full-selfdriving-hardware [https://perma.cc/EY9X-8FBK]. 
sense, and so Tesla owners would be put in a bit of a quandary if states adopt consumer training requirements: under state law, they might have to obtain a special endorsement to drive the car in 2017, but they will no longer need that endorsement mere months later when the car becomes fully driverless. ${ }^{239}$

Nevertheless, despite these issues, the need for greater consumer training remains, as does support for states to mandate that drivers complete such training, prior to operating semi-autonomous cars. ${ }^{240}$

\section{ADDITIONAL RECOMMENDATIONS}

In addition to the changes to federal and state law advocated above, there are a number of other gaps and uncertainties in our understanding of the risks posed by semi-autonomous cars, as well as a number of risks inherent in the legislative process, that merit careful thought and discussion. They are as follows.

\section{A. Pressing Research Needs}

NHTSA "has already begun research to evaluate the ability of drivers to stay engaged while HAVs are performing part (or all) of the driving task," but a great deal more research needs to occur on the safety of Level 2 vehicles, in particular, and of the ability of drivers to maintain focus while such vehicles operate in semi-autonomous modes. ${ }^{241}$ Indeed, the available data seems to be contradictory. On the one hand, a number of studies (discussed above) have shown that drivers in Level 2 vehicles have a tendency to become distracted and even reckless in some scenarios. ${ }^{242}$ On the other, a recent study of Teslas equipped with the Autopilot Technology Package suggested that the Level 2 technology onboard these vehicles may actually make them safer:

[NHTSA's Office of Defects Investigation] analyzed mileage and airbag deployment data supplied by Tesla for all MY 2014 through 2016 Model S and 2016 Model X vehicles equipped with the Autopilot Technology Package, either installed in the vehicle when sold or through an [overthe-air] update, to calculate crash rates by miles travelled prior to and after Autopilot installation. ... The data show that the Tesla vehicles' crash rate dropped by almost 40 percent after Autosteer installation. ${ }^{243}$

While this was only one study of one type of Level 2 vehicle, it raises an interesting possibility that has not yet been explored in any depth by researchers: the possibility that, even with drivers prone to distraction, Level 2 vehicles are still safer than Level 1 or Level 0 vehicles. ${ }^{244}$ This is a question that merits much more formal and

239. See WeAVER, supra note 68, at 182.

240. See supra Part III.

241. NAT'L Highway Traffic SAFEty Admin., supra note 9, at 37.

242. Goodall, supra note 122; Llaneras et al., supra note 117, at 94.

243. NAt'L Highway Traffic Safety Admin., supra note 2, at 10.

244. See id. 
extensive study. As Consumer Reports notes, while Level 2 vehicles "have the potential to improve safety ... we can't make that determination until there is a sufficient body of evidence in the field comparing accident records of cars with the [Level 2] systems, to those without." 245

There is another, more nuanced and abstract issue pertaining to semi-autonomous cars that also warrants greater thought and research: the possibility that use of Level 2 systems over time may diminish driving skills in general. Several researchers explain:

There is a possibility of overreliance upon automation when drivers are able to use a L2 or L3 automated driving system for some period of time. That is, the potential exists for drivers to constantly seek to activate the automated driving component of the vehicle after becoming familiar with the automation and how it functions. Researchers have postulated that, over time, this overreliance can possibly lead to degradation in driver skill as the reinforcement from constant engagement in the driving task is now lacking. This issue is of concern in the aviation domain, where pilot skill has been observed to suffer in the presence of frequent and continuous use of automated functions. ${ }^{246}$

Scholars have expressed concern about this "learned incompetence issue" since well before Level 2 vehicles were available to consumers, and there does not yet seem to be any available data that would confirm or assuage those fears. ${ }^{247}$

There appear, however, to be three main possibilities in regards to this learned incompetence issue. First, learned incompetence may not, in fact, be a real phenomenon, and driving skills amongst the U.S. driver population may remain unchanged in the face of greater consumer adoption of autonomous and semi-autonomous vehicles (the "no problem" scenario). Second, learned incompetence may be a real and demonstrable phenomenon with little actual relevance or risk associated with it given the fast pace at which newer and greater forms of automation are being introduced into U.S. vehicles by tech companies and manufacturers. In essence, the greater degree of independence of the vehicles themselves may wind up compensating for the greater degree of dependence of human drivers on automated systems to drive their vehicles safely (the "irrelevant problem" scenario).

Third, learned incompetence may be a real and demonstrable phenomenon with a significant degree of risk associated with it. In this scenario, there could, for instance, be a fairly lengthy gap in time between vehicles being fully autonomous (and thus capable of driving safely on their own) and semi-autonomous vehicles being driven in large numbers and increasingly eroding the driving abilities of U.S. drivers. This diminished human-driving capacity, in turn, could create a great deal of risk on the road when semi-autonomous vehicles reach the limits of their technologies, and yet,

245. Tesla's New Autopilot: Better but Still Needs Improvement, CONSUMER ReP. (Oct. 8, 2016), http://www.consumerreports.org/tesla/tesla-new-autopilot-better-but-needs-improvement [https://perma.cc/V2WQ-Y9BY].

246. Nat'L Highway Traffic Safety Admin., supra note 25, at 25.

247. Douma \& Palodichuk, supra note 52, at 1164. 
human drivers have little ability to regain control of their cars and respond to immediate driving situations appropriately, quickly, and effectively (the "actual problem" scenario). The "no problem" and "irrelevant problem" scenarios obviously deserve little concern on the part of policymakers and legislators. The "actual problem" scenario, however, does. Only greater research will reveal which of these three scenarios is most likely and whether and how lawmakers need to respond.

\section{B. The Coming Issues with Level 3 Cars}

While Level 2 vehicles present a unique set of issues arising out of the need for human drivers to continuously supervise these vehicles while driving in semi-autonomous mode, ${ }^{248}$ Level 3 vehicles present a related yet ultimately distinct set of issues. As a brief reminder, Level 3 vehicles can drive themselves in some situations but require a human driver to be prepared to reassume control of the vehicle when signaled to do so by the vehicle itself. ${ }^{249}$ Drivers of Level 3 vehicles need not monitor their automobiles at all times but must be available to intervene when necessary. ${ }^{250}$ This requires a careful negotiation between giving drivers greater leeway to take advantage of the higher level of automation by engaging in non-driving related activities (by, for instance, subjecting them to less distracted driving liability) while ensuring that those drivers can retake control of the car quickly and effectively when needed. ${ }^{251}$ This, in turn, will require careful assessment of two factors.

First, NHTSA needs to conduct or commission research about how long it takes for the average human driver to retake control of a vehicle safely when signaled to do so. This is a critical piece of information that may implicate significant aspects of Level 3 vehicle design and the overall safety of these vehicles:

Level 3 vehicles provide . . warning time, but the precise amount of time needed is unknown. The NHTSA guidance does not specify an appropriate warning time, although some guidance can be found in highway design standards. The American Association of State Highway and Transportation Officials (AASHTO) recommends highway designers allow 200 to 400 meters for a driver to perceive and react to an unusual situation at $100 \mathrm{~km} / \mathrm{hr}$. This corresponds to 7 to 14 seconds, much of which is beyond the range of today's radar at 9 seconds. In an emergency, a driver may be unable to assess the situation and make an ethical decision within the available time frame. In these situations, the automated vehicle would maintain control of the vehicle, and by default be responsible for ethical decision making. ${ }^{252}$

Another set of tests showed that "it takes an average of 3 to 7 seconds, and as long as 10 , for a driver to snap to attention and take control, even with flashing lights and

248. See supra notes 243-246 and accompanying text.

249. SAE INT'L, supra note 13.

250. NAT'L HighwAy Traffic SAFEty Admin., supra note 25, at 9-10.

251. Davies, supra note 45.

252. Goodall, supra note 122. 
verbal warnings," which is a bit more reassuring than the 7 to 14 second range provided immediately above, but also highlights the uncertainty surrounding this issue and the need for more research. ${ }^{253}$

Second, NHTSA needs to determine what, if any, driver notification or warning methods are most effective at generating quick and effective responses from human drivers. The City of New York poses the question more simply in its public comments to the Policy: "How will a driver who is reading, napping, or surfing the web be alerted that they need to take control?"254 Vehicles must be able to accurately convey information to human drivers who may be "disengaged from the driving task" and paying little or no attention to vehicle performance or road conditions, while also not providing so much information that drivers begin to "tune out" those warning signals or turn them off altogether. ${ }^{255}$ Research may also show that $n o$ warning systems are effective at this task and thus that (a) manufacturers should incorporate driver monitoring systems into Level 3 cars, and (b) drivers of Level 3 cars should be subject to the same driver distraction laws as drivers of Level 2 cars. ${ }^{256}$ Again, only greater research can provide needed guidance on this issue.

\section{The Risks Inherent in Lawmaking}

While lawmakers may have an initial impulse to regulate both semi-autonomous and fully autonomous vehicles heavily and as soon as possible, this approach involves a significant amount of risk. As I discuss at length in a prior article:

There are "inherent danger[s] in trying to design legislation too soon for new technology." Such legislation could stifle development and thus undermine the benefits that the technology has to offer. Moreover, given that the United States is still within early stages of driverless car roll out, it is difficult to accurately assess what the biggest regulatory needs will be. ${ }^{257}$

Level 2 vehicles are particularly complicated in this regard because, unlike Level 3 , 4 , and 5 vehicles, they are both already on U.S. roads, increasing in number every day, and yet still largely under-researched and misunderstood. This creates a set of risks in attempting to regulate them.

253. Davies, supra note 45.

254. City of New York, Comment Letter on Federal Automated Vehicle Policy (Nov. 22, 2016), https://www.regulations.gov/document?D=NHTSA-2016-0090-1016 [https://perma.cc/ AYK2-BPTV].

255. Nat'L Highway Traffic Safety Admin., supra note 9, at 22.

256. See id.; see also City of New York, supra note 254 ("Driver inattention is a key factor in crashes in cities, and NHTSA needs to ensure that Level 2, 3 and 4 AVs do not further contribute to this problem. For this reason, we believe that driver engagement monitoring should be incorporated, particularly in conjunction with Level 2 and 3 AV systems. Use of the AV system should be limited when drivers are insufficiently attentive.").

257. Pearl, supra note 41, at 70 (alteration in original) (footnotes omitted) (quoting WEAVER, supra note 68, at 61). 
On the one hand, under-regulating semi-autonomous cars may increase the risk of traffic accidents and fatalities. ${ }^{258}$ Distracted driving remains a significant problem in the United States, and the growing popularity of semi-autonomous cars may only make that problem worse. On the other hand, over-regulating semi-autonomous vehicles may slow the adoption of all kinds of autonomous vehicles, even the Level 4 and 5 vehicles that are likely to be significantly safer, by making people mistrust the technology or subjecting them to so many laws that using those vehicles seems like too much of a hassle or liability issue. ${ }^{259}$ This hesitation, in turn, could undermine the profound safety benefits highly automated vehicles have to offer. This has happened in the past with other forms of automation and should give us pause here. ${ }^{260}$ Overregulation may also heighten the risk of states creating a "patchwork" of inconsistent regulations that would make it difficult for automobile manufacturers to generate vehicles that comply with regulations in all jurisdictions. ${ }^{261}$

There is not a clear way to resolve the tension inherent in regulating new forms of technology. The best approach would appear to be to proceed with caution, to base legislative and regulatory efforts on actual data and research results, and to regulate one step at a time rather than attempting to design and impose an overarching (and thus potentially overbearing) regulatory regime in one fell swoop.

\section{CONCLUSION}

The United States is in the midst of a revolution in transportation. Semi-autonomous vehicles are already available to consumers, with more models arriving to market nearly every month. Fully autonomous cars will be available within the decade. The federal government and states throughout the nation have responded by rushing to pass laws designed to regulate the fully autonomous cars that have not yet arrived while largely ignoring the semi-autonomous cars that are already on U.S. roads. This was made especially clear in the Federal Automated Vehicle Policy that NHTSA released in late 2016, which explicitly states that it is intended to provide guidance with regard to the regulation of highly automated vehicles (Levels 3, 4, and 5) rather than partially automated vehicles (Level 2). This is an extremely troubling oversight.

Despite the fact that semi-autonomous vehicles rely on continuous human supervision to operate safely, a growing body of research demonstrates that the drivers of Level 2 vehicles are prone to distraction. In at least one instance, this has had deadly consequences. ${ }^{262}$ Furthermore, an even more troubling set of studies suggests that both drivers and sellers of Level 2 vehicles do not have a strong understanding of the limitations of the semi-autonomous features of their cars and are thus at risk of failing to intervene and retake control of the vehicle when necessary. ${ }^{263}$

Both the federal government and states should pass laws and regulations designed to address these safety issues with semi-autonomous cars. Consistent with the current

258. See supra Part III.

259. NAT'L Highway Traffic Safety Admin., supra note 10.

260. John D. Lee \& Katrine A. See, Trust in Automation: Designing for Appropriate Reliance, 46 Hum. FACTORS 50 (2004).

261. Law Office of Stephen E. Selander, supra note 101.

262. See supra notes 129-140 and accompanying text.

263. See supra Part III.B.2. 
jurisdictional division in the regulation of motor vehicles in the United States, the federal government should pass a series of laws designed to regulate the design of semi-autonomous cars, whereas states should pass laws aimed at regulating how drivers operate these vehicles.

Congress should grant NHTSA the ability to create and administer a premarket approval system for semi-autonomous vehicles. This would give NHTSA the ability to regulate the safety of semi-autonomous cars before accidents and fatalities occur and also minimize the ability of car manufacturers to beta-test semi-autonomous systems that may not yet be safe on unwitting consumers. Additionally, the federal government should require car manufacturers to install attention warnings systems that would alert drivers when their attention has wandered from the road. Finally, the federal government should limit the ability of car manufacturers to name semi-autonomous systems something that would suggest to consumers that these systems are more independent or fully developed than they actually are.

States, in turn, should pass laws that regulate the behavior of drivers of semiautonomous cars. In particular, they should forbid such drivers from tampering with or disabling driver monitoring systems that would limit their ability to become distracted while the semi-autonomous systems in their vehicles were engaged. Furthermore, owners of semi-autonomous cars should be required to install routine overthe-air software updates that make their vehicles safer and correct critical safety defects. Lastly, states should require that drivers of these vehicles obtain proper training as to the capabilities and limitations of semi-autonomous vehicles and of critical differences between, for instance, Level 2 and Level 3 driverless cars.

While a significant amount of research needs to be conducted on a number of issues surrounding semi-autonomous cars, sensible safety laws and regulations can minimize the risk that issues with semi-autonomous cars now will detract from consumer acceptance and adoption of significantly safer fully autonomous cars later. Given the immense number of benefits that those vehicles stand to offer to the United States, particularly by reducing traffic accidents and fatalities, ruining our great experiment with automated driving by failing to regulate early stages of the technology appropriately would not only be tragic but a profoundly missed opportunity to protect human life both now and later. 